\title{
ADVERSE SELECTION SPIRALS
}

BY

\author{
Piet de Jong And Shauna Ferris
}

\begin{abstract}
This article discusses risk classification and develops and discusses a framework for estimating the effects of restrictions on risk classification. It is shown that expected losses due to adverse selection depend only on means, variances and covariances of insurance factors and rates of uptake of insurance. Percentage loadings required to avoid losses are displayed. Correlated information, such as family history, is also incorporated and it is seen how such information limits losses and decreases required loadings. Although the evidence suggests that adverse selection is not, at present, a severe problem for insurers, this might change if the authorities impose restrictions on risk classification and/or customers gain an informational advantage (such as better knowledge of their own risk levels). Application is made to unisex annuity pricing in the UK insurance market.
\end{abstract}

\section{KEYWORDS}

Adverse selection, genetic testing, premium loading, insurance demand, equilibrium pricing, unisex pricing.

\section{INTRODUCTION}

Risk classification is often controversial, particularly when it makes insurance expensive or unattainable for some members of the community. Insurers often argue that risk classification is necessary to avoid adverse selection. But how can we assess the potential costs of adverse selection?

Macdonald (1999) makes a persuasive case for actuaries to quantify the consequences of adverse selection using data and models. In a classic article, Rothschild and Stiglitz (1976) study problems related to adverse selection. The analysis is in terms of indemnity contracts and two groups identical in every respect except the risk probability. It is shown that under certain assumptions there is no "pooling equilibrium", i.e. there is no contract, specifying both the price and quantity of insurance, which is optimal to both groups. Instead, they argue there may be a "separating" equilibrium, where each group is offered its 
own price and quantity combination. Combined price and quantity equilibria are argued to be competitive to price equilibrium because in a competitive environment a price only equilibrium will always be competed away in favor of a combined price and quantity equilibrium since both buyers and sellers will be better off under the latter. It follows that for a large number of groups each group would be offered its own price quantity contract.

We depart from the Rothschild and Stiglitz (1976) analysis because its assumptions rule out behavioural features we are trying to model. In particular:

- Our contracts are not necessarily indemnity contracts;

- Customers can often buy multiple insurance contracts, which undermines price-quantity competition;

- In life insurance, a dollar before death may not have the same utility to the purchaser as a dollar after death, which makes utility analysis more problematic.

The further sections of this paper are as follows. Section 2 gives the substantive background to risk classification controversies. Section 3 outlines some of the literature on modelling adverse selection in insurance including multi-state models. Section 4 discusses the interrelationships between risk and demand for insurance setting the stage for the formal analysis in Section 5. Section 6 considers uniform break even premium as a strategy for avoiding adverse selection losses. Section 7 deals with alternative loss mitigating strategies. These alternative strategies are explored formally in sections 8 and 9. Section 10 describes the adverse selection spiral where it is seen that the spiral is related to the price sensitivity of demand. Section 11 proposes a model for demand as function of the premium loading and explores the conditions for pricing equilibrium. Section 12 applies the methodology to quantify the impact of unisex pricing in the UK annuities market.

\section{RISK CLASSIFICATION ISSUES}

In 1706, in London, Charles Povey set up the Trader's Exchange. He invited subscribers to pay a few shillings into a life insurance fund. Each subscriber could nominate any person to be the life insured. In the event of a death, the subscriber could make a claim. At the end of each quarter, a specified sum would be divided equally among the claimants.

\footnotetext{
"Since policy-holders were not required to have an insurable interest in their nominees and could therefore choose whom they pleased, it can have surprised no one except Povey himself that, as he complained in July 1707, 'many Impositions were put upon the Office in its Infancy, by Peoples Subscribing upon the Lives of unhealthy Persons, and upon such too that [it] was morally impossible that they should live to a twelve Months end." (Dickson, 1960)
} 
Naturally, the large number of deaths reduced the benefit payment per claimant making the scheme correspondingly less attractive to new subscribers. Within a few years, the Trader's Exchange mutual life insurance society was dissolved.

This illustrates some of the problems which arise as a result of adverse selection. When all people are charged the same premium - regardless of their risk - then the insurance pool creates a transfer of funds from the group of lowrisk participants to the group of high-risk participants. If the low-risk participants find this unacceptable, the system may not be viable.

Mr Povey realised this was a problem. In the future, he decided, it would be desirable to require each subscriber to "give a reasonable Account of the Health of the Person whose Life they intend to Subscribe upon" (Dickson, 1960 , p. 24). In other words, underwriting appears necessary for the development of a healthy life insurance business.

Other life offices soon attempted to identify high-risk applicants and charge differential premium rates. By 1725, they were charging a bit extra for publicans, a bit less for people who had already survived smallpox, a bit more for married women of child-bearing age, and so on.

Insurers (and others such as public health officials) were soon collecting and pooling data in order to identify and assess mortality risks. Over the 300 years since the demise of the Traders' Exchange, insurers developed underwriting rules based on rating factors such as age, sex, occupation, family history, medical history, lifestyle (smoking, alcohol), and so on.

However, risk classification has often been surrounded by controversy. In some cases, there is strong opposition to the use of certain rating factors to classify risks. The main issues are examined in the next few subsections.

\subsection{Is risk classification fair?}

Actuaries often suggest that risk classification systems should be "actuarially fair." The American Academy of Actuaries (American Academy of Actuaries Committee on Risk Classification, 1980) suggests that a system will be fair if:

"Differences in prices among classes reflect differences in expected costs with no intended redistribution or subsidy among classes."

However, the general public might not agree that "actuarial fairness" is really fair in any ethical sense. This is particularly likely to be an issue when risk classification is based on factors which are beyond the control of the individual (i.e. "not his fault") (Chuffart, 1995).

Most people would agree that it is fair to charge extra premiums for smokers or racing car drivers. After all, those people have chosen a lifestyle which increases their mortality risk. However, many people do not think that it is fair to charge extra premiums to people who are blind, or people who carry a genetic mutation which increases risk. There is a natural tendency to feel that 
"There, but for the grace of God, go I." For example (Skipper and Black, 2000 , p. 644) cite figures indicating $67 \%$ of people believe it is fair to charge higher premiums to those who smoke but only $14 \%$ believe it is fair to charge higher premiums to those with a predisposition to cancer.

In recent years there have been a number of fierce controversies about risk classification systems which discriminate against people who are already disadvantaged, often through no fault of their own. For example:

- In the United States, some health insurers discriminate against women who have been victims of domestic violence. They argue that these women have a higher-than-average probability of making claims in the future, so it is "actuarially fair" (Hellman, 1997). But several state legislatures have passed laws to prevent such discrimination.

- In the United States, many insurers have begun to use credit history in underwriting for motor vehicle insurance and homeowners insurance. There is statistical evidence to show that people with a poor credit rating have higher loss ratios, so it may be regarded as actuarially fair. But many are concerned that this will create an additional financial burden (in the form of higher premiums) for low-income people who are already struggling. The American Academy of Actuaries noted that "using credit history is often perceived to be in conflict with what society considers as fair, particularly if the individual's score is affected by catastrophic events such as divorce, medical problems, or loss of a job." (Wright et al., 2002).

- In the Netherlands, the Health Council has opposed the use of genetic testing for life insurance underwriting, stating that "We find it unacceptable that people affected from birth with a genetic predisposition should be faced with additional social obstacles, and that their relatives should also be at a disadvantage in this way." (Leigh, 1996, p. 19).

If insurers are prevented from using certain rating factors, then this may create cross-subsidies between groups - the low risk members of society will subsidize the high-risk members of society. From a public policy perspective, this may be regarded as a desirable outcome. Rothschild and Stiglitz (1997) point out the logic behind this attitude.

"Any concave social welfare function will prefer the distribution of income in a society without underwriting to the distribution of income in a society with underwriting. To see this, imagine yourself behind a Rawlsian veil of ignorance: ask whether you would prefer to be born in a society without underwriting. If you are risk-averse, you will choose the society without underwriting."

However, there may be limits to the generosity of the low-risk members of society. Although surveys show that some people would be willing to pay higher premiums to subsidize the more unfortunate members of the community, they don’t want to pay more than 5\% or 10\% extra (Chuffart, 1995). 


\subsection{Is risk classification an unacceptable breach of privacy?}

In some cases, life insurers may ask insurance applicants very personal questions - and people resent this intrusion into their privacy. This is particularly likely to be a problem when people may suffer from discrimination if certain personal information is revealed.

As an example, consider the impact of AIDS on insurance. In some countries, insurers began to ask people about their sexual preferences and practices information which many people might be reluctant to reveal, especially when there is a social stigma associated with certain sexual preferences. If people are unwilling to reveal the truth then data becomes unreliable for rating purposes.

The use of genetic test data in insurance is also raising concerns, particularly in countries where people with genetic defects were the victims of eugenicists in the 1930s. For example, in Germany, people with Huntington's were killed in accordance with the government's health strategy (Harper, 1992).

\subsection{Does risk classification have undesirable consequences?}

If insurers use health data in underwriting, then some people may decide it would be better to avoid or delay testing. This may mean that they do not obtain an accurate diagnosis of their health risks, and hence they might not obtain the best possible treatment.

This became an issue in the UK in the 1980s, in relation to HIV testing. The insurers asked applicants to state whether or not they had had an HIV test. This disclosure was required even if the test result was negative. Insurers argued that people probably would not bother to take a test unless they believed themselves to be at risk - possibly because of high-risk practices such as unprotected sex or needle-sharing. So people who had been tested were required to answer a more detailed lifestyle questionnaire. Some doctors began to warn patients against taking HIV tests because it might damage their chances of getting insurance, even if the test results were negative. As a result, insurers were strongly criticized by the Health Minister, the government's Chief Medical Officer, AIDS charities, and medical specialists, who argued that this approach was having negative public health consequences, because it discouraged people from having tests. They argued that people should only be required to report a positive HIV test result. This issue caused a great deal of adverse publicity for the insurance industry, along with threats of legislative restrictions on underwriting. Eventually, in July 1994, the Association of British Insurers recommended that insurers should delete underwriting questions about negative HIV tests (Leigh, 1996; Hopegood, 1990; Worsfold, 1991; Hall, 1991; Papworth, 1991; Jones, 1991; Sullivan, 1991; Harris, 1994).

The same type of controversy has affected genetic testing. If insurers charge higher premiums for people who have tested positive for a genetic disorder, then people might be discouraged from taking the tests: and hence miss out 
on vital medical treatment. Several studies have provided evidence to support this view (Lapham, 1996).

\subsection{Is risk classification equitable to individuals?}

Ideally, risk classification sorts people into homogeneous groups - so that people in the same group have the same risk, and can be charged the same premium.

However, risk classification is not an exact science and in practice often results in heterogeneous groups, leading to some inequity. Naturally, the people who are disadvantaged are likely to object.

As an example, consider the controversy about unisex rating in pension schemes. On average, women live longer than men. So pension funds would usually provide a lower annual payment to women (in return for the same lump sum). This may provide equity between groups (men and women) - but it does not necessarily provide equity for individuals within each group. When all known risk factors are taken into account, many women have shorter life expectancies than the average man, and many men have longer life expectancies than the average woman: that is, there is considerable overlap in life expectancies. If risk classification is based solely on sex, while ignoring other risk factors, then this will lead to outcomes which are not even "actuarially" fair (in particular, it will be unfair to women in poor health). In the USA, these arguments were crucial to the outcome of the Manhart case (Doeer, 1984). The court decided that gender-based pension fund rules were a contravention of the Equal Employment Opportunity Act: although the gender-based rules were "fair to classes", they were not "fair to individuals."

This "overlap" argument has recently been used by the advocates of unisex pension benefits in the UK (Curry and O'Connell, 2004).

Heterogeneity is particularly likely to arise when there is no causal connection between the rating factor and the risk - e.g. when a rating factor is used as a proxy for some other causal risk factor which is difficult to measure.

In the past, life offices often used race as a rating factor. Mortality rates for blacks were higher than mortality rates for whites. In this case, race was being used as a proxy for social disadvantage - black people were likely to be poorer and hence suffered all the extra mortality risks associated with poverty.

The problem of heterogeneity within rating groups is also a problem in general insurance. Naturally, those who are most adversely affected are most likely to complain about inequity. De Ravin and Rump (1996) provides the following account from the Australian motor vehicle insurance industry. Members of a motorcyclists association visited the government regulator to complain about the high premium rates applied to motorcycles.

\footnotetext{
"The argument mounted by the motorcyclists was that the risk factors adopted in the premium relativity setting were inadequate. Therefore the premium relativity setting process was not a comprehensive and satisfactory risk classification scheme. The reason, they argued, why the premiums for motorcyclists
} 
were so high, was that people who were likely to take high risks on the roads were over-represented amongst the motorcyclist population. ... They said that it was unfair that the premiums for sensible motorcyclists should be inflated by the actions of a few maniac riders; that cost could more equitably have been spread across the whole of the insuring population."

Similarly, consider the use of sex as a rating factor in motor vehicle insurance. It is true that on average, women drivers have lower claims costs than men. However, this difference does not derive from an innate superiority of driving skills arising from possession of an extra X chromosome. Instead, the difference in accident rates reflects differences in driving patterns. In general, women don't drive as far as men, and they don't drive on the same type of journeys as men. That is, sex is being used as a proxy for exposure to risk. Clearly, rating by sex improves equity for some people (those who fit the stereotype) but it imposes an unfair financial penalty on others (e.g. men who have a low exposure to risk). This has led to some controversy over the use of sex as a rating factor for motor vehicle insurance, in both the USA and Canada (Nova Scotia Insurance Review Board, 2004).

Promislow (1987) has pointed out that some risk classification schemes might, in fact, create greater inequity overall, although this depends on the method used for measuring inequity.

\subsection{Is risk classification really necessary?}

Insurers usually argue that risk classification is necessary - if they are not allowed to classify risks, then an adverse selection spiral might develop, pushing up premium rates and making insurance unaffordable for most people. Insurers can provide examples such as the Traders' Exchange (mentioned above), the MIRAS problems in the UK (Leigh, 1990; Le Grys, 1998), the introduction of non-smoker discounts in the USA, and the difficulties arising from community rated health insurance in Australia (Banks et al., 1997).

However, others argue that the risk of an adverse selection spiral has been overstated. This spiral is only likely to occur under specific circumstances, e.g. when the elasticity of demand for insurance products is high.

In practice, despite dire predictions of disaster, the elimination of rating factors does not always lead to disruption of the insurance market. In some cases, the elimination of a rating factor might only lead to a relatively small increase in premium rates, which can be absorbed by the market.

Some have suggested that insurers might be "crying wolf" about the risks of adverse selection, seeking to preserve their "Right to Underwrite." For example Hall (1999) writes:

"The problem with this argument [i.e. re adverse selection] is that it can easily be overblown. In my experience, actuaries are sometimes like the boy who cried wolf when it comes to adverse selection. Adverse selection has failed to materialize in several areas of health insurance, despite doomsday predictions." 
In the UK, insurers have tried to persuade the government to allow the use of genetic test data in underwriting. The insurance industry argued that if they were not allowed to use genetic test data, then they might suffer from adverse selection, increasing premiums for all and possibly reducing the availability of some types of insurance. However, when pressed, they found it difficult to estimate the probable cost. As Macdonald (2000, p. 4) put it:|

"The insurers could not say whether lack of access to genetic test results might cost the industry $£ 1$ or $£ 1,000,000,000$."

In the same vein, Thomas (2001) writes:

“...there is potential actuarial justification for permitting insurers' access to genetic test results. The potential justification is that such access is essential to the viability of private insurance markets. But there is currently no evidence, in any class of insurance, that this either is or will become the case. The most recent actuarial studies suggest that even under the most unfavourable assumptions, ignoring genetic tests and family history would have little effect on most insurance markets."

If there are good public policy reasons for restricting the use of certain rating factors, then insurers will need to justify their use of these rating factors by quantifying the adverse effects of such restrictions.

\section{CONSEQUENCES OF RESTRICTIONS ON RISK CLASSIFICATION}

So here is our problem: How can we measure the financial impact of restrictions on risk classification? How can we quantify the costs of adverse selection? How are insurers likely to respond to when accurate risk classification is not permitted?

Accurate risk classification avoids the problem of adverse selection since each risk is charged the actuarially fair premium rate. Inaccurate risk classification implies subsidies from low-risk to high-risk groups. Cross subsidies create incentives for adverse selection.

Initially, adverse selection may create losses for the insurer. But insurers will naturally react to these losses, for example by charging higher premiums. How can we determine the amount of the additional premiums required? The additional cost may increase over time as the mix of customers changes in response to price changes.

To quantify the adverse selection losses and the increases in premiums required to prevent them, we must model the precise connection between the premium rate, the average demand for insurance by different customers, and the expected claims costs across different risk groups.

Macdonald (1999) develops and discusses two approaches for quantifying adverse selection losses in relation to genetic risks: a Markov approach and the random future lifetime approach. The Markov approach (Hoem, 1969, 1988; 
Norberg, 1995; Macdonald, 1997; Subramanian and Lemaire, 1999) follows risks through time as they transit between different states corresponding to different characteristics. States are classified according to genetic composition, whether genetic testing has been undertaken, the results of such genetic tests, insurance status, and so on.

Random lifetime models (Bowers et al., 1986; Gerber, 1990) parametrize the survival function in terms of frailty value associated with each individual. For example the force of mortality (or hazard) may be assumed to be a standard force multiplied by a frailty value which varies with individuals. For both the Markov and random lifetime models, a detailed picture is built up of mortality and insurance rates of different individuals. The detailed model is simulated to arrive at likely costs of adverse selection. The approach is "bottom up" in that adverse selection costs are quantified using detailed assumptions about risks and individual behavior.

Crucially, these models depend on estimates of transition intensities, i.e. the propensity to insure and the amount of insurance which will be purchased under different conditions. These rates are likely to be affected by the individual's own risk, his knowledge of his risk, and the premium rate he will be charged for this risk. However, there is relatively little empirical evidence available on these matters. As Macdonald (1999) points out, there is a need for further research into insurance-buying behavior.

For example, Armstrong et al. (2003) have looked at the insurance-buying behavior of women who test positive for a genetic mutation associated with breast cancer. Pauly et al. (2003) have attempted to estimate the elasticity of demand for insurance, relative to both price and risk.

\section{Modelling AdVERSE SELECTION}

Suppose there is a population which consists of many individuals who have different levels of risk and different levels of demand for insurance. Let a random variable $g$ denote the level of risk for an individual. In the life insurance context, $g$ might reflect the "frailty" of any individual, i.e. a multiple of the standard force of mortality.

Individuals buy insurance. Let $X$ denote the claims cost per unit of insurance with $\mu \equiv E(X)$. The expected claims cost varies with $g$ with $\mu_{g} \equiv E(X \mid g)$ denoting the expected claims cost given $g$. Assume $g$ contains all the information available beforehand useful for predicting $X$. Thus knowing $g$, any additional information $h$ will not change the expected claims cost. In other words $E(X \mid g, h)=E(X \mid g)$. If insurers can classify risks using $g$, and charge premiums accordingly, then the risk premium rate for an individual with risk $g$ is $\mu_{g} \equiv E(X \mid g)$.

At a specified price, each individual in the population has a particular level $r$ of demand for insurance. In the life insurance context $r$ can denote the sum insured which an individual seeks to purchase. In the general or casualty 
insurance context, i.e. where the policy is a contract for indemnity against losses, $r$ could indicate whether or not insurance is purchased, or the fraction of the loss that is insured.

The individual's demand for insurance $r$ is a function of many factors, including price or the premium. According to Pauly et al. (2003), some of the key factors which are known to influence demand for insurance are self-evaluated current health status, wealth, income, and number of children. Thus there is likely to be a correlation between the amount of insurance required $r$, and the level of risk $g$. The correlation may be positive or negative, although insurers are naturally more likely to be worried about positive correlations. As shown in the next section, adverse selection becomes an issue to the insurer when there is a positive correlation between $r$ and $g$ within one premium rating group.

Analysts often distinguish between "active" and "passive" adverse selection. Active adverse selection implies that a high-risk customer deliberately buys additional insurance to take advantage of the "bargain" provided by low premium rates. Passive selection occurs when the correlation between risk and demand for insurance is a side effect of other factors affecting demand such as those mentioned above (e.g. wealth, income, risk aversion, etc). For example, life insurance demand might depend on:

- The individual's perceptions of his own state of health. If an individual believes himself to be in a poor state of health, he might be more likely to buy life insurance (and less likely to buy an annuity). Studies have shown that an individual's own estimate of his mortality risk is positively correlated with actual mortality outcomes (Hurd and McGarry, 2002; McGarry and Finkelstein, 2003). That is, there is a positive correlation between self-perceived risk and the true risk $g$.

- The individual's level of income. Life insurance policies need not be indemnity policies - but the principle of indemnity may be a consideration in determining the amount of insurance needed. If a breadwinner dies, he might want insurance which will allow his family to maintain their standard of living - so the sum insured might be chosen based on the present value of the breadwinner's future earnings. Several studies have shown that there a higher level of income is likely to be associated with lower mortality rates, particularly for males (Knox and Tomlin, 1997). That is, there is a negative correlation between income and mortality risk.

- Level of risk aversion. People who are more risk averse might be more likely to buy insurance, and might also be likely to have lower-than-normal mortality rates. For example risk-averse people might be less likely to smoke, drink to excess, take drugs, drive dangerously, or choose risky pastimes. If cautious people have lower risks and also buy more insurance, then there will be a negative correlation between $r$ and $g$. This effect has been noted in relation to long term care insurance (McGarry and Finkelstein, 2003). 
- Number of dependents. A married person with small children may have a greater need for life insurance. A number of studies have found a correlation between marital status and mortality risk, i.e. married people have lower mortality rates (Brown and McDaid, 2003). This may arise from selection (healthy people are more likely to get married); from changes in lifestyle; or from the mutual care and support obtained by living with others.

- Factors related to the marketing of insurance. For example in the early days of insurance, some life offices marketed to the clerical and medical professions, who were expected to have lower-than-normal mortality rates. These days, marketing might be directed to people who own certain credit cards, or belong to particular professional associations, or live in particular geographical areas. These marketing factors may be either positively or negatively correlated to the risk level $g$.

Demand is also affected by random variation: Was the customer at home when the insurance agent knocked? Was the agent particularly persuasive in explaining the need for a higher sum insured? Did the customer's best friend die recently in a car crash?

\section{AdVERSE SELECTION LOSSES ARISING FROM COMMUNITY BASED RATING}

Now consider the problem from the insurer's perspective. An individual comes into the insurance office and seeks to buy $r$ units of insurance. Throughout the analysis we ignore expenses, capital costs, the insurer's profit loadings, etc.

If insurers classify risks using $g$, and charge premiums accordingly, then the risk premium rate for an individual with risk $g$ is $\mu_{g} \equiv E(X \mid g)$ per unit sum insured. It follows that the insurer's expected profit on each policy is zero,

$$
E\left(r X-r \mu_{g} \mid g\right)=E(r X \mid g)-r_{g} \mu_{g}=0,
$$

where $r_{g} \equiv E(r \mid g)$. Hence there will be no cross-subsidies between groups.

Theorem 5.1. Suppose the notation and conditions stated above. Then $\operatorname{cov}(r, X \mid g)=$ 0 . Further $\operatorname{cov}(r, X)=\operatorname{cov}\left(r_{g}, \mu_{g}\right), E(r X \mid g)=r_{g} \mu_{g}$ and $E(r X)=E\left(r_{g} \mu_{g}\right)$.

To prove the theorem, note $r$ is available beforehand. Hence $E(X \mid g)=E(X \mid g, r)$ and

$$
\operatorname{cov}(r, X \mid g)=\operatorname{cov}\{r, X-E(X \mid g)\}=\operatorname{cov}\{r, X-E(X \mid g, r)\}=0 .
$$

Further

$$
\begin{gathered}
\operatorname{cov}(r, X)=E\{\operatorname{cov}(r, X \mid g)\}+\operatorname{cov}\{E(r \mid g), E(X \mid g)\}=\operatorname{cov}\left(r_{g}, \mu_{g}\right), \\
E(r X \mid g)=\operatorname{cov}(r, X \mid g)+E(r \mid g) E(X \mid g)=r_{g} \mu_{g}, E(r X)=E\{E(r X \mid g)\}=E\left(r_{g} \mu_{g}\right),
\end{gathered}
$$

completing the proof. 
Now suppose insurers cannot charge premiums based on risk $g$. In practice insurers might not be able to use $g$ to set premiums: $g$ might not be observable; it might not be cost-effective to ascertain $g$; or legislative restrictions might prevent the use of $g$ in rating. A randomly chosen customer buys insurance at rate $r$ and, in the absence of risk classification, might be charged a premium based on the expected claims cost per unit sum insured for the population, i.e. $\mu \equiv E(X)$. The expected loss per policy is

$$
E(r X-r \mu)=E(r X)-E(r) E(X)=\operatorname{cov}(r, X)=\operatorname{cov}\left(r_{g}, \mu_{g}\right)=\sigma_{r} \sigma \rho,
$$

where $\sigma_{r}$ and $\sigma$ are the standard deviations of $r_{g}$ and $\mu_{g}$ respectively, and $\rho$ is their correlation.

Definition. Adverse selection is said to exist if $\operatorname{cov}\left(r_{g}, \mu_{g}\right)>0$.

Thus the loss (1) is positive if and only if there is adverse selection, and adverse selection exists if the rate $r_{g}$ is positively related, in a linear sense, to $\mu_{g}$ since correlation is a measure of linear association. If there is adverse selection and the insurer charges $\mu$ then the insurer will make a loss and the system will not be in equilibrium.

If $\rho<0$, then the insurer will make a profit. In a competitive market this may also be an unstable situation, since competitive pressures may lead insurers to try other pricing schemes, as described below. Of course competition is not always based on price, for example life offices might compete on investment returns and/or bonus rates instead of premium rates; and general insurance markets have not always been price-competitive, particularly in the era when prices were determined by tariffs.

The premium $\mu=E(X)$ implies cross subsidies between customers. When $\rho>0$ the good customers pay more than their expected claims cost, and the high risk customers pay less. If demand is a function of the premium loading, i.e. the ratio of the premium to the individual's expected claims cost, this may lead to changes in the distribution of $r_{g}$, the demand for insurance, and the changing mix of the insured population may create instability in the premium rates, i.e. an adverse selection spiral. However, this does not always occur. The conditions which lead to a spiral are discussed below.

\subsection{Adverse selection losses with two risk groups}

Suppose we have a population which includes just two groups, $g=0$ and $g=1$. People in group 1 are high-risk people, e.g. they might carry a genetic mutation which is known to increase risk, and $g=0$ individuals are "low-risk." The proportion of people in the high-risk group is $p=E(g)$ and the average amount of insurance purchased by people in group $g$ is $r_{g}$ and the expected claims cost per unit sum insured for any person chosen at random is

$$
E(X)=\mu_{0}+p\left(\mu_{1}-\mu_{0}\right),
$$


Charging the same premium for both groups, and assuming that the premium rate is set at $E(X)$, then the cost of adverse selection for the insurer is

$$
\operatorname{cov}(r, X)=\left(r_{1}-r_{0}\right)\left(\mu_{1}-\mu_{0}\right) p(1-p) .
$$

Expressing the loss as a proportion of expected premium income, yields

$$
\lambda=\frac{p(1-p)\left(r_{1}-r_{0}\right)\left(\mu_{1}-\mu_{0}\right)}{\left\{p r_{1}+(1-p) r_{0}\right\}\left\{p \mu_{1}+(1-p) \mu_{0}\right\}}=\frac{p(1-p)}{\left(p+\frac{1}{i_{r}}\right)\left(p+\frac{1}{i_{\mu}}\right)},
$$

where

$$
i_{r}=\frac{r_{1}-r_{0}}{r_{0}}, \quad i_{\mu}=\frac{\mu_{1}-\mu_{0}}{\mu_{0}} .
$$

These formulas are useful in determining the effects of different risk classification restrictions. For example suppose $20 \%$ of people carry a gene mutation which increases the expected claims cost on a life insurance insurance policy by $50 \%$. Suppose that initially, the high risk members of the population cannot be identified (either by the insurers or the individual). Hence we might expect that the average sum insured is the same for both risk groups, say $\$ 100$ per person in the population.

Now suppose a new genetic test is developed, which permits people to determine their own risk category. Suppose insurers are not allowed to use this information to classify risks. If we make the pessimistic assumption that all the high-risk individuals will buy twice the normal amount of insurance, then

$$
i_{r}=\frac{200-100}{100}=1, \quad i_{\mu}=\frac{1.50 \mu_{0}-\mu_{0}}{\mu_{0}}=0.50, \quad \lambda=\frac{0.2(1-0.2)}{(0.2+1)(0.2+2)}=0.0606 \text {. }
$$

Thus the expected adverse selection loss, expressed as a proportion of premium income, is $6.06 \%$. The premium income is $1.32 \mu_{0}$ and the claims cost is $1.40 \mu_{0}$.

More sophisticated models such as Macdonald (1999) or Subramanian et al. (1999) might be used to obtain a more realistic estimate of the rate of genetic testing and subsequent insurance purchases by the high risk group, i.e. to determine $i_{r}$.

\section{UNIFORM BREAK EVEN PREMIUM RATING}

Insurers will not willingly sell insurance at a loss for any extended period of time. If adverse selection occurs, then the insurer might decide to apply a uniform "adverse selection" loading to the premium, designed to achieve a "break even" result.

Let the loading be $\lambda$ and hence each customer is charged $(1+\lambda) r \mu$. Equating expected premium income to expected claims cost requires 


$$
E\{r X-(1+\lambda) r \mu\}=0 \Rightarrow \lambda=\frac{\operatorname{cov}(r, X)}{E(r) E(X)}=\frac{\operatorname{cov}\left(r_{g}, \mu_{g}\right)}{E\left(\mu_{g}\right) E\left(r_{g}\right)}=\frac{\sigma_{r} \sigma}{\mu_{r} \mu} \rho .
$$

The loading $\lambda$ is called "covariance" loading and is the proportional increase in premium required to ensure, on average, zero underwriting losses. The loading $\lambda$ is large if the coefficients of variation of $r$ or $X$ are large or if their correlation is large.

The zero loss premium per unit sum assured is

$$
\varepsilon(X) \equiv(1+\lambda) E(X)=E\left(\mu_{g}\right)+\frac{1}{E\left(r_{g}\right)} \operatorname{cov}\left(r_{g}, \mu_{g}\right) .
$$

The last expression in (4) shows the break even premium $\varepsilon(X)$ is the ordinary premium $E(X)$ plus a loading proportional to $\operatorname{cov}(r, X)$. This is reminiscent of the "variance" premium principle of Bühlmann (1970) where the ordinary premium is loaded by a term proportional to the variance.

The break even premium $\varepsilon(X)$ can also be written as

$$
\varepsilon(X)=\frac{E(r X)}{E(r)}=\frac{E\left(r_{g} \mu_{g}\right)}{E\left(r_{g}\right)} .
$$

This is a proper expectation where, compared to $E(X)=E\left(\mu_{g}\right)$, the density $f(g)$ of $g$ is replaced by the "adverse selection" density $r_{g} f(g) / E\left(r_{g}\right)$. Thus the break-even premium rate $\varepsilon(X)$ is the expected value of the claims cost, weighted by demand for insurance. Put another way, $\varepsilon(X)$ is the expected cost associated with a randomly drawn dollar of premium income.

\subsection{Covariance loading with two risk groups}

Suppose as before two risk groups, $g=0$ and $g=1$. The proportion of people in the high risk group, $g=1$, is $p$. What extra premium will the low-risk group have to pay in order to subsidise the high risk group? If this amount is high, then the low risk group is likely to object to the proposed rating structure.

The break even premium is

$$
\begin{gathered}
\varepsilon(X)=E\left(\mu_{g}\right)+\frac{\operatorname{cov}\left(r_{g}, \mu_{g}\right)}{E\left(r_{g}\right)}=(1-p) \mu_{0}+p \mu_{1}+\frac{p(1-p)\left(r_{1}-r_{0}\right)\left(\mu_{1}-\mu_{0}\right)}{(1-p) r_{0}+p r_{1}} \\
=\mu_{0}+p\left(\mu_{1}-\mu_{0}\right)+\frac{p(1-p)}{p+\frac{1}{i_{r}}}\left(\mu_{1}-\mu_{0}\right) .
\end{gathered}
$$

Hence the premium rate payable by the low-risk group is the sum of

- The "actuarially fair" premium $\mu_{0}$ for the low risk group 
- A "solidarity premium" $p\left(\mu_{1}-\mu_{0}\right)$ which spreads the extra risks of the high risk group across the whole population.

- An additional loading, corresponding to the last term in (6), which reflects the "adverse selection" effect, i.e. the costs arising from the differential rates of insurance for $g=0$ and $g=1$ risks.

When a risk factor is beyond the control of the individuals (e.g. a genetic risk), then the solidarity premium component may be considered socially desirable, in the Rawlsian sense described previously. However, the low-risk group might be more unhappy about the "adverse selection" component of the premium: they might regard this extra cost as the high-risk people deliberately "taking advantage" of the system. Indeed, this may be true. However the selection effect might be passive, e.g. the high-risk group may have higher levels of demand for insurance as a result of other factors such as wealth, risk aversion, number of dependents, etc.

Figure 1 plots the combined solidarity and adverse selection premium effect

$$
\phi\left(p, i_{r}\right) \equiv p+\frac{p(1-p)}{p+\frac{1}{i_{r}}}=\frac{\left(i+i_{r}\right) p}{1+p i_{r}},
$$

as a function of $0<p<1$ and for different $0 \leq i_{r} \leq 100$. The 45 degree line corresponds to $i_{r}=0$ and hence there being no difference in rates of insurance between the two groups. In this case, for given difference in extra risk $\mu_{1}-\mu_{0}$, the entire increase in premium varies directly with $p$, the proportion of people in the high risk group. The first line above the 45 degree line corresponds to $i_{r}=1$, i.e. the high risk people buy twice as much insurance as the low-risk people (on average). The next line above that shows the loading when $i_{r}=2$, and so on up to the highest line which represents $i_{r}=100$. The difference in a particular curve from the 45 degree line represents the extra loading which arises from differential rates of insurance. Figure 1 illustrates that adverse selection costs can be a major component when $p$ is low and $i_{r}$ is large.

For example, consider the example discussed previously, i.e. a genetic defect which affects $20 \%$ of the population and causes a $50 \%$ increase in mortality. If both groups buy the same amount of insurance, then low-risk group pays a loading of $10 \%$ on top of their actuarially fair premium. This is the "solidarity premium", i.e. the additional risk for the higher risk is spread evenly across the whole population. This is the point on the graph where $p=0.20$ and $i_{r}=0$, on the diagonal.

But now suppose that adverse selection occurs: perhaps the high risk people perceive that they are getting a bargain, paying less than the fair premium for their insurance, and they decide to buy more insurance. If the high-risk group buys twice as much insurance as the low risk group, then the low risk group will pay a total premium rate of $1.1667 \mu_{0}$, i.e. the $16.67 \%$ higher than their fair premium. This is the point on the graph where $p=0.20$ and $i_{r}=1$. The 


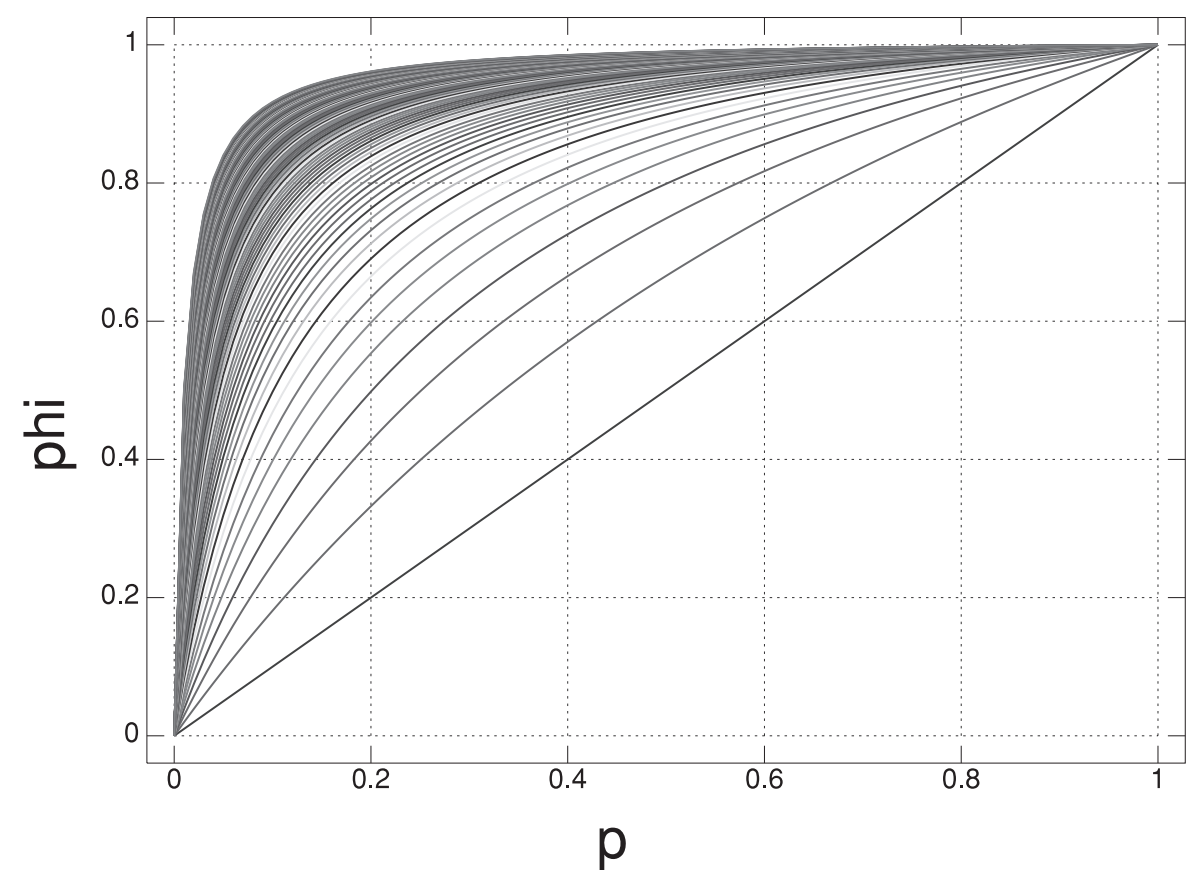

FIGURE 1 . Solidarity plus adverse selection costs $\phi\left(p, i_{r}\right)$ plotted against $0 \leq p \leq 1$ for $i_{r}=0,1, \ldots, 100$.

additional loading of $6.67 \%$ may be regarded as the adverse selection component of the premium.

Clearly, if regulators wish to control the cost to the low-risk group, then limits on the amount of insurance purchased by the high-risk group might be useful.

\subsection{Application to life insurance}

As noted above, the break-even premium is equivalent to

$$
\varepsilon(X)=\frac{E(r X)}{E(r)}=\frac{E\left(r_{g} \mu_{g}\right)}{E\left(r_{g}\right)} .
$$

In life assurance, we can determine the break-even premium rate by using mortality tables which are weighted by the sum insured. If adverse selection is occurring, so that the higher-risk lives are buying more insurance than the low-risk lives, then the "dollar" weighted mortality rates will be higher than the "lives" weighted mortality rates. 
Even 150 years ago, actuaries were aware of the potential for adverse selection, and they began analysing their mortality experience on an "amounts" basis as well as on a "lives" basis. For example, Spens (1854) decided to calculate what he called the "financial mortality" of the London Equitable, arguing that this would "represent the truth with much more accuracy." Other actuaries followed in his footsteps, and such analyses are now a routine part of the analysis of both life insurance and annuitants' experience.

For example the Institute of Actuaries and Faculty of Actuaries publishes (Wilkie et al., 1999) pensioners' mortality tables based on both "lives" and "amounts." The "amounts" table became the basis for the PA(90) tables which were commonly used for calculation of premiums and reserves for pensioners for many years.

Problems arise if the covariance is not stable over time, i.e. if the relationship between the demand $r$ and $g$ is unstable. So any life office which uses amounts-weighted mortality tables would need to review experience regularly.

In particular, problems can arise if the different risk groups have different reactions to any premium rate changes. Normally, we would expect that as price rises, demand will fall. If the demand for insurance falls uniformly (in percentage terms) across all risk groups, then the average premium rate for the group will remain stable. However, if low risk individuals are relatively more sensitive to price increases, then any change in the premium rates might lead to an increase in adverse selection, and hence the previously-calculated breakeven premium would be inadequate to cover expected claims - possibly leading to an increase in premium rates, followed by an adverse selection spiral. The potential for such a spiral depends on the shape of the demand curves for the different risk groups and is discussed in $\S 10$.

\section{Adverse SElection mitigation Strategies}

An insurer might be reluctant to load premiums to cover adverse selection losses since this might lead to a loss of business and/or an adverse selection spiral. Instead, the insurer might seek to control the risk of adverse selection by changing the terms and conditions of policies on offer.

Since the adverse selection loss is given by $\operatorname{cov}(r, X)=\sigma_{r} \sigma \rho$, insurers might reduce the costs of adverse selection through:

- Restricting the variance of $r$, the sum insured. Typically, life insurers would be reluctant to offer policies where the sum insured is unusually large. The insurer might attempt to restrict the variation in $r$, the sum insured, e.g. by setting limits on the amount of insurance which any individual can buy, either as a fixed sum or as a multiple of income levels. Financial underwriting limits adverse selection.

- Restricting the variance of $X$, the claim cost. In order to reduce the variation in $X$, the claims cost per unit, the insurer can try to reduce the 
heterogeneity of his customers, e.g. by avoiding high-risk customers. Ideally this could be done by better risk classification, but it might be possible to attain the same result by other methods, such as targeted marketing. For example,

- in Australia, the government regulated the premium rates for compulsory motor vehicle insurance, so that insurers were not able to charge the fair premium rate for people in higher-risk districts. Some insurers responded by making it less convenient for drivers in those districts to buy insurance.

- in Australia, some insurers offer life insurance with minimal underwriting; but this product is marketed to groups who meet certain criteria, e.g. they are members of certain professional associations and/or have credit cards which are only available to high-income individuals

- The insurer might be able to reduce the variation in the claim cost by designing products which have a lower transfer of mortality risk. For example, in life insurance, endowment assurances are less sensitive to mortality risk than whole of life insurances, which in turn are less sensitive to risk than term insurances. Whole of life policies with increasing sums insured (e.g. withprofit policies) carry less mortality risk than non profit policies. In the early days of life insurance, a person in doubtful health was often offered an endowment insurance instead of the whole of life policy he or she had initially requested.

- Restricting the correlation between sum insured and expected claims cost. In order to reduce the correlation between $X$ and $r$, the insurer might set standard sums insured, so that the customers have little or no choice in the level of insurance (e.g. in group life policies where the sum insured is fixed by a formula).

- In some cases, the insurer might be able to undermine the customer's informational advantage. Suppose that people can estimate their own mortality risk reasonably accurately over the short term, but are less accurate in predicting their long term risk. An insurer could protect himself against adverse selection by selling policies which pay a reduced sum insured in the event of death within the first $n$ years. Such provisions were common in the early days of industrial assurance (Hoffman, 1900), and similar strategies were adopted when non-medical insurance was first introduced (Nicoll, 1904). At present, some Australian insurers sell "guaranteed issue" life insurance policies, i.e. policies which have no medical underwriting - but there are often provisions such as

- during the first 2 years the death benefit will only cover death by accident; and/or

- the benefit will not be paid if, within 5 years prior to the policy commencement date, the life insured had "any illness, injury, or condition, or symptoms thereof, that led to or contributed to the death of the life insured." 


\section{SUM INSURED AS A PROXY RATING FACTOR}

Instead of applying a uniform covariance loading on all policies, the insurer might decide to use the sum insured as a proxy rating factor. Suppose data show a positive correlation between $r$ and $g$. Then a customer who applies for higherthan-normal sums insured might be assumed to be a higher-than-normal risk, and hence could be charged a higher premium rate. Obviously

$$
E\{r X-r E(X \mid r)\}=0 .
$$

Thus using the sum insured $r$ as a proxy rating factor leads to zero adverse selection loss. This is equivalent to having a different unit price for each quantity of insurance.

This leads to the concept of price-quantity equilibrium and price-quantity competition in insurance markets, as proposed by Rothschild and Stiglitz (1976). Their analysis assumes risk-averse customers with different risk probabilities, where asymmetric information prevents accurate risk classification. The analysis shows that:

- there cannot be a pooling equilibrium, i.e. there is no single price-quantity combination where different groups of customers will buy the same amount of cover; but

- a separating equilibrium may exist i.e. where customers with different risks buy different price-quantity packages;

- in some circumstances a competitive insurance market may have no equilibrium.

Effectively, the insurer can offer a limited number of price-quantity combinations or "products": customers with different risk levels will prefer different products, and hence the customer's own choices will reveal information about his/her own risk level. The difficulty lies in choosing a set of products which will effectively segment the market. In order to do so successfully, each insurer must also take account of the range of products available from other insurers. A considerable amount of work has been done, looking at the combinations of products packages which might be offered by insurers in competitive markets. In some cases (Rothschild and Stiglitz, 1976) an equilibrium may not exist.

How well does this model fit the life insurance market? As Rothschild and Stiglitz (1976) point out, the crucial assumption for the price-quantity model is that

"customers purchase but a single contract or equivalently that the total amount of insurance purchased by any one customer is known to all companies that sell to him."

The model is undermined if a high-risk customer can buy a number of smaller policies from a number of different insurers. 
In life insurance, the empirical data suggests that many customers do indeed buy multiple policies (Philipson and Cawley, 1996). It is certainly true that many life offices ask their customers about policies held with other offices, and would apply stricter underwriting standards to those applicants who ask for unusually large sums insured. However, insurers do not usually charge higher premium rates to customers who wish to purchase higher sums insured.

If there is indeed a positive correlation between the risk level $g$ and the amount of insurance purchased $r$, then the sum insured should be useful in determining risk, and the insurer might charge a higher premium to those with higher sums insured.

However, based on the evidence available from life insurers, this is not likely: on the contrary, insurers are more likely to offer discounts for large sums insured (Philipson and Cawley, 1996). If anything, the evidence suggests that there is a negative correlation between risk and the demand for insurance: people who buy insurance have lower mortality rates than the population average; and those who buy large sums insured tend to have lower mortality rates than those who buy smaller policies. That is, in life insurance, there is a negative correlation between $r$ and $g$.

Selection by the insurers provides a partial explanation for this phenomenon; but it might also be due to "passive selection" based on differences in wealth and risk aversion. Even in the earliest days of insurance, Babbage (1826) noted that insured lives had lower mortality than the general population. He argued that:

\begin{abstract}
"At all the insurance offices the nominee is warranted to be in good health at the time of the contract being made; and on this ground alone, we ought to expect a much smaller mortality amongst that class of persons than among the general population of the country. Another circumstance which contributes much to diminish the rate of mortality among the assured is that they are all selected from the middle and higher ranks of society, and are consequently exempt from many of the sources of unhealthiness to which the poor are liable .... Seasons of scarcity affect materially the health of the poor; but the class who make assurances are generally placed beyond their influence."
\end{abstract}

Even within the group of insured lives, people with higher sums insured tend to have lower mortality rates. This is hardly news - even in the 1880's, actuaries in both Germany (Meikle, 1886) and the UK (Stenhouse, 1886) had observed this relationship. Wealthier people can afford to buy more insurance, and wealthier people have lower mortality rates.

The same relationship has been observed in more recent Australian and American mortality studies. In the USA, the Society of Actuaries Experience Studies show that policies with larger sums insured have lower mortality rates than polices with smaller sums insured (Society of Actuaries Individual Life Experience Committee, 2004). Furthermore, in an analysis of adverse selection, Philipson and Cawley (1996) found that in the American life insurance market 
- insurance prices fall with quantity (discounts are often given for large sums insured); and

- risk is negatively correlated with the quantity of insurance purchased.

They explained this result by pointing to the life insurer's ability to assess risks accurately by underwriting, i.e. they suggested that

"the superiority of buyer information is overstated in the standard theory of adverse selection; while buyers may have better idiosyncratic information, sellers may have better systematic information from observing claims across many buyers."

However an alternative explanation is given by Pauly et al. (2003). They argue that information asymmetry does exist, but elasticity of demand is so low that an adverse selection spiral is unlikely to arise.

"While the authors ... interpret their results as evidence that, in some way, insurers must have found out everything insureds know, such a scenario seems implausible on its face. In both settings, the key risk is limited to an individual's health state, and that state is notoriously hard to measure objectively. However, even if the buyers indeed know more than the sellers of insurance, serious adverse selection would not occur if those buyers were sluggish in their willingness to respond to that information. Real consumers, after all, have more on their minds than paying attention to small bargains in insurance markets. In short, low demand responsiveness to risk and premium variation can also cause markets with truly asymmetric information to avoid the instability and bias associated with adverse selection."

In Australia, the Institute of Actuaries of Australia analysed life insurance experience by both "policy counts" and "sums insured" (Barn et al., 2004). They found that the actual-to-expected claim ratios by sum insured were lower than the ratios by policy count, for all three classes of business (death cover, trauma insurance, and total and permanent disability business). This result was consistent with the results of earlier investigations. The Australian actuaries suggested that

"policies with higher sums insured may experience lighter mortality through more stringent underwriting or because of the link between mortality and socio-economic status."

In the life insurance market, the "wealth effect" and the "adverse selection" effect work in opposite directions. But in the annuity market, where longevity creates risks for the life office, both the "wealth effect" and the "adverse selection" effect will work in the same direction: people who are healthy and wealthy are more likely to buy a large annuity and more likely to create losses for the life office.

In the annuity markets, researchers in several countries including Australia (Doyle et al., 2002), the UK (Finkelstein and Poterba, 2002; Murthi et al., 1999), 
and the USA (Mitchell and McCarthy, 2001) have found evidence of adverse selection. For example, in Mitchell and McCarthy (2001) international data from the USA, the UK, and several other countries are considered. They found that

"adverse selection associated with the purchase of international annuities reduces mortality rates by at least $25 \%$ in the international context."

So can annuity-providers segment the market by offering different price-quantity combinations? Once again, it would be difficult to set higher annuity rates for higher amounts, since customers could easily buy several small annuities at a low rate instead of buying a single annuity at a higher rate. In the UK, the market data suggests that annuity rates for large annuities are actually somewhat better than the rates available for small annuities. For example, Murthi et al. (1999) found that a lump sum of $£ 100,000$ would buy $£ 8,726$ per annum while a lump sum of $£ 10,000$ would buy only $£ 851$ per annum. They suggest that the savings in administration costs for the large policies outweigh the additional longevity costs.

However, it is possible to design annuity products which have varying amounts of mortality risk transfer: theoretically different products would appeal to customers with different mortality risks. This seems to be consistent with the empirical evidence in the UK market. Finkelstein and Poterba (2002) found that shorter-lives annuitants bought products which had a guarantee period; and longer-lived annuitants appeared to choose products which were back-loaded (i.e. had annual payments which increased over time, in real terms).

\section{RISK CLASSIFICATION BY PROXY VARIABLES}

Suppose that an insurer cannot charge premiums based on the true to risk factor $g$, either because it is impractical to collect the data or because it is not permissible. It might be possible and permissible to charge premiums based on some other variable $h$ rather than $g$. Hopefully $h$ will be correlated with $g$. Examples might include:

- in life insurance, $h$ might be a family history of Huntington's disease and $g$ is the genetic mutation which causes the disorder

- in life insurance, race may be used as a proxy for risks caused by social disadvantage

- in motor vehicle insurance sex may be used as a proxy for the exposure to risk (i.e. the number of kilometers driven in a year)

- in motor vehicle insurance age might be used as a proxy for years of driving experience

- if insurers are not allowed to ask questions about sexual preferences for AIDS underwriting, then they might simply charge higher premiums to all single males above age 30 living in certain areas or in certain occupations 
To what extent can the insurer eliminate adverse selection losses, by using a proxy variable?

If we classify risks according to $h$ for rating purposes, then the overall population is divided into two or more subpopulations (homogeneous in $h$ but heterogeneous in $g$ ). We can calculate the expected adverse selection loss per policy within each rating group, which will be $\operatorname{cov}(r, X \mid h)$. Then, averaging these losses over the whole population, the expected adverse selection loss per policy

$$
E\{\operatorname{cov}(r, X \mid h)\}=\operatorname{cov}(r, X)-\operatorname{cov}\{E(r \mid h), E(X \mid h)\} .
$$

Hence the proportionate reduction in the adverse selection cost is

$$
\frac{\operatorname{cov}\{E(r \mid h), E(X \mid h)\}}{\operatorname{cov}\{E(r \mid g), E(X \mid g)\}}=\frac{\operatorname{cov}\{E(r \mid h), E(X \mid h)\}}{\operatorname{cov}\left\{r_{g}, \mu_{g}\right\}} .
$$

The reduction is positive provided the conditional rate of insurance and conditional claims cost, conditioning on $h$, are positively correlated.

Special cases of the above result are $h$ is constant, $h=r$ and $h=g$. When $h$ is constant no rating information is used, the premium is $E(X)$ and adverse selection cost is $\operatorname{cov}(r, X)$, as before. If $h=r$ (rating on sum insured) or $h=g$ (complete underwriting) the premium is $E(X \mid r)$ or $E(X \mid g)$ and the adverse selection loss is, in both cases, zero, as before.

When $E(X \mid h)$ is linear in $h$, as when $(X, h)$ is normally distributed then

$$
E(X \mid h)=E(X)+\operatorname{cov}(X, h)\{\operatorname{cov}(h)\}^{-1}\{h-E(h)\} .
$$

with a similar expression for $E(r \mid h)$ if the latter is linear in $h$. The proportional reduction in adverse selection costs on account of $h$ is then

$$
\frac{\operatorname{cov}(r, h)\{\operatorname{cov}(h)\}^{-1} \operatorname{cov}(h, X)}{\operatorname{cov}(r, X)}=\frac{\rho_{r h} \rho_{h X}}{\rho},
$$

where the subscripted $\rho$ 's indicate correlations and the last equality assumes $h$ is scalar. The reduction is large if $h$ correlates highly with both $r$ and $X$.

\subsection{Two proxy risk groups}

When $h$ is binary then conditional expectations given $h$ are linear in $h$ and the formulas (8) and (9) apply. If $q$ is equal to the probability of $h=1$ then the reduction in the cost of adverse selection is

$$
\operatorname{cov}(r, X)-\operatorname{cov}(r, X \mid h)=\left(r_{1}-r_{0}\right)\left(x_{1}-x_{0}\right) q(1-q),
$$

where $r_{0}, r_{1}, x_{0}$ and $x_{1}$ are the means of $r$ and $X$ given $h=0$ and $h=1$. 
TABLE 1

AN EXAMPLE OF COUNTER-PRODUCTIVE RISK CLASSIFICATION

\begin{tabular}{l|cc|cc}
\hline \hline \multirow{2}{*}{} & \multicolumn{2}{|c|}{ Males } & \multicolumn{2}{c}{ Females } \\
\cline { 2 - 5 } & $\begin{array}{c}\text { Annuity } \\
\text { value }\end{array}$ & $\begin{array}{c}\text { Average amount } \\
\text { of annuity }\end{array}$ & $\begin{array}{c}\text { Annuity } \\
\text { value }\end{array}$ & $\begin{array}{c}\text { Average amount } \\
\text { of annuity }\end{array}$ \\
\hline Unhealthy & 10 & 2 & 12 & 1 \\
Healthy & 14 & 4 & 16 & 3 \\
Average & 12 & & 14 & \\
\hline \hline
\end{tabular}

Note that the introduction of a proxy rating variable will not necessarily reduce adverse selection costs: if $\operatorname{cov}(X, h)$ is negative then adverse selection costs will increase. We might have a situation where $g$ is positively correlated to $r, h$ is positively correlated to $g$, but $h$ is negatively correlated to $r$.

To illustrate, consider the situation displayed in Table 1 dealing with a hypothetical population of pensioners, where $50 \%$ of the population is male and $50 \%$ female, and half of each gender group is in good health. Using unisex rating based on the population average annuity rate, then we would charge a premium of $13=(10+12+14+16) / 4$ per unit sum insured, leading to premium income of 130 against claims of 136 and a loss of 6 . Switching to gender-based rating, again based on population averages, then we would charge 12 per unit sum insured for the males and 14 per unit sum insured for the females. The premium income would fall to 128 , without any change in benefit payments, creating a loss of 8 . This problem arises because the high risk group (females) has a lower average demand than the low risk group (males) - a situation which might be common in pension funds, where pension amounts are linked to salary and length of service. The loss could only be eliminated by adding loadings to the premiums to cover the adverse selection loss.

\subsection{Break-even loading within proxy groups}

To mitigate adverse selection losses insurers can once again load premiums: either separately for each group $h$, or applying the same percentage loading to all groups. No new analysis is required if a separate loading is calculated for each $h$ : the loaded adverse selection premium to avoid losses in group $h$ is $\left(1+\lambda_{h}\right) E(X \mid h)$ where

$$
\lambda_{h}=\frac{\operatorname{cov}(r, X \mid h)}{E(r \mid h) E(X \mid h)} .
$$

This shows that the premium rate for any group $h$ will be a function of both the expected claims cost in the group, and the amount of adverse selection within that group. 
TABLE 2

US MALE AND FEMALE LIFE EXPECTANCIES AT AGE 65

\begin{tabular}{lccc}
\hline \hline & Male & Female & Difference \\
\hline Population & 16.2 & 19.7 & 3.5 \\
Compulsory Annuitants & 18.9 & 20.9 & 2.0 \\
Voluntary Annuitants & 20.0 & 22.7 & 2.7 \\
\hline \hline
\end{tabular}

If the low-risk class exhibits greater adverse selection than the high-risk class, this will narrow the differential in premium rates. For example, consider the data in Table 2 from Mitchell and McCarthy (2001). In the overall population, the difference between female and male life expectancies is about 3.5 years. However for annuitants, the difference is significantly smaller. This suggests that males annuitants and pensioners display greater adverse selection than females. Mitchell and McCarthy (2001) concluded that "selection between female voluntary annuitants and the population is one-third lower than among men."

If we also adjust for the size of the annuity, ie. weighting by amounts instead of lives, the differential might be even narrower. For example, according to the 1991-1994 UK pensioners data, (Wilkie et al., 1999, Table 5) the difference between lives-weighted female and male life expectancies is 3.3 years; the difference between amounts-weighted female and male life expectancies is only 2.9 years.

How can this discrepancy be explained? The explanation might lie in passive selection by income levels. An Australian study by Knox and Tomlin (1997) found that the link between income and mortality was quite strong for men, i.e. the men with large pensions tended to have lower mortality rates. But for women, the link between income and mortality was much weaker. Both UK and Australian studies of mortality differences by socio-economic class confirm that the mortality differences for males were greater than the mortality differences for females (Murthi et al., 1999; Australian Bureau of Statistics, 2001).

Others have suggested that women are more risk averse, and possibly less confident of their own ability to invest large lump sums: hence even women in poorer health might choose to buy annuities.

\subsection{Aggregate break-even loading}

A second approach is where premiums are calculated as $(1+\lambda) E(X \mid h)$ where $\lambda$ does not depend on $h$. Thus each $h$ group is charged the actuarially fair premium for that group loaded by a common percentage amount, independent of $h$. The expected loss is

$$
\begin{gathered}
E\{r X-(1+\lambda) r E(X \mid h)\}=E[r\{X-E(X \mid h)\}]-\lambda E\{r E(X \mid h)\} \\
=\operatorname{cov}(r, X \mid h)-\lambda[E(r) E(X)+\operatorname{cov}\{r, E(X \mid h)\}]
\end{gathered}
$$


Equating to zero and solving for $\lambda$ gives the loading for zero loss:

$$
\lambda=\frac{E\{\operatorname{cov}(r, X \mid h)\}}{E(r) E(X)+\operatorname{cov}(r, E(X \mid h))}=\frac{\operatorname{cov}(r, X)-\operatorname{cov}\{E(r \mid h, E(X \mid h))\}}{E(r) E(X)+\operatorname{cov}(r, E(X \mid h))} .
$$

The loading (10) is less than the "raw" zero loss loading in (3) on two counts. First, in the numerator, $\operatorname{cov}(r, X)$ is reduced by $\operatorname{cov}\{E(r \mid h), E(X \mid h)\}$. Second, in the denominator $E(r) E(X)$ is increased by $\operatorname{cov}\{r, E(X \mid h)\}$. Of course both of these are assumed positive.

Note that when a proxy factor is used to create heterogeneous rating groups, then this might create an adverse selection spiral within one group. For example, suppose that initially we have a small group of high risk individuals, say people affected with the mutation for Huntington's disease (HD). If there is no risk classification, then the cost of these risks will be spread across the entire population, and the extra cost might be too small to create an adverse selection spiral. Now suppose that a proxy factor is used, e.g. family history. All people with an HD family history will be charged a much higher premium, even if they do not bear the deleterious mutation. If these people can subsequently take a genetic test in order to determine their own risk level, then it is likely that people who test negative will lapse their high-premium policies. The people who test positive will retain their high-premium policies, creating an adverse selection spiral within the rated-up group. Ultimately, it seems likely that insurers will charge premiums on the assumption that anyone with an HD family history carries the deleterious mutation. This suggests that a ban on genetic underwriting might not be very effective, if insurers can still use family history for underwriting.

\subsection{Different pricing strategies across insurers}

So which type of loading should an insurer use, break-even loading within proxy groups or aggregate break-even loading across groups? Both rating methods achieve zero loss. But what happens if different insurers use different methods? The market cannot be in equilibrium. The insurers charging the higher premium in a given proxy group will lose market share in that group. This will not create any losses for the insurer loading each proxy group separately, since for that insurer, each proxy group is priced to break even. However the insurer who charges aggregate break even loading will suffer losses since it is cross subsidising proxy groups.

\section{AdVERSE SELECTION SPIRALS}

The loading required to break-even depends on the covariance between $X$ and $r$. However, if the demand for insurance changes as a result of changes in the 
level of premiums, then insurers will have a difficult time dealing with adverse selection.

The covariance between $X$ and $r$ will remain constant if either

- demand is price-inelastic, or

- both high risks and low risks drop out of the system at the same rate when premiums increase.

However, if a premium increase leads the low risk people to drop out of the system at a higher rate, then the insurance market might move into an adverse selection spiral.

Theoretically, an insurance market should be in equilibrium if we classify risks accurately and charge the actuarially fair value to each individual. Now suppose that we must charge the same premium to different risks (either because we cannot distinguish the risks, or because legislation forbids the use of such rating systems). Will an equilibrium exist? How can we determine the premium rate which will equate the supply and demand for insurance?

If we ignore expense loadings and so on, then the system will be in equilibrium when the premium rate is equal to the average claims cost per unit sum insured, averaged over all customers.

Define for each given premium $\pi, r_{g}(\pi) \equiv E(r \mid g, \pi)$. Thus $r_{g}(\pi)$ is the demand given a premium rate $\pi$ and risk level $g$. The system will be in equilibrium when $\pi=\pi^{*}$ where $\pi^{*}$ is such that

$$
\pi^{*}=\frac{E\left\{\mu_{g} r_{g}\left(\pi^{*}\right)\right\}}{E\left\{r_{g}\left(\pi^{*}\right)\right\}} \equiv \varepsilon\left(\mu_{g} \mid \pi^{*}\right) .
$$

As noted previously, $\varepsilon\left(\mu_{g} \mid \pi\right)$ is the expectation of $\mu_{g}$ with respect to the density proportional to $r_{g}(\pi) f(g)$ where $f(g)$ is the density of $g$ in a population (pool) of potential insurance consumers. Thus it is the expectation of $X$ with respect to "adverse selection measure" $r_{g}(\pi) f(g) / E\left\{r_{g}(\pi)\right\}$ at the given $\pi$.

The premium $\pi^{*}$ is an equilibrium premium in two senses. First, there is zero excess profit and hence there is no incentive for insurers to leave or enter the market. Second, consumer demand is satisfied at this premium rate.

The existence of an equilibrium premium $\pi$ satisfying (11) can be proved in the following way. Since $\varepsilon\left(\mu_{g} \mid \pi\right)$ is an expectation of $\mu_{g}$ it follows $\inf _{g}\left(\mu_{g}\right) \leq$ $\varepsilon\left(\mu_{g} \mid \pi\right) \leq \sup _{g}\left(\mu_{g}\right)$. Thus $\pi-\varepsilon\left(\mu_{g} \mid \pi\right)$ is negative when $\pi=0$ and positive for suitably large $\pi$. Hence, assuming continuity, $\pi=\varepsilon\left(\mu_{g} \mid \pi\right)$ for some $\pi=\pi^{*}$.

Unfortunately $\pi^{*}$ may be a premium where all the good risks have dropped out of the system and only the worst risk remains insured. At this point the premium rate is equal to the expected claims cost per unit sum insured for the worst risk in the population. This would be regarded as an unsatisfactory outcome.

The iterative process leading to $\pi^{*}$, if it exists, is properly called the "adverse selection spiral." Formally, the spiral may be described as follows. Suppose initially insurance companies charge $\pi_{0}=E\left(\mu_{g}\right)$. At this premium demand is 
$E\left\{r_{g}\left(\pi_{0}\right)\right\}$ and the resulting adverse selection loss $E\left\{\mu_{g} r_{g}\left(\pi_{0}\right)\right\}-\pi_{0} E\left\{r_{g}\left(\pi_{0}\right)\right\}$. The premium $\pi_{0}$ is thus increased to cover the loss to yield $\pi_{1}$ :

$$
\pi_{1} \equiv \pi_{0}+\frac{E\left\{\mu_{g} r_{g}\left(\pi_{0}\right)-\pi_{0} E\left\{r_{g}\left(\pi_{0}\right)\right\}\right\}}{E\left\{r_{g}\left(\pi_{0}\right)\right\}}=\varepsilon\left(\mu_{g} \mid \pi_{0}\right) .
$$

This result is not surprising: the new premium is the expected value of the risk under the revealed adverse selection measure based on $\pi_{0}$. In turn $\pi_{1}$ will yield a loss leading to an increase in premiums to $\pi_{2} \equiv \varepsilon\left(\mu_{g} \mid \pi_{1}\right)$ and so on. Thus the sequence of prices

$$
\pi_{0}=E\left(\mu_{g}\right), \pi_{1}=\varepsilon\left(\mu_{g} \mid \pi_{0}\right), \pi_{2}=\varepsilon\left(\mu_{\mathrm{g}} \mid \pi_{1}\right), \pi_{3}=\varepsilon\left(\mu_{\mathrm{g}} \mid \pi_{2}\right), \ldots,
$$

is the adverse selection spiral. The limit, if it exists, is a fixed point $\pi^{*}=\varepsilon\left(\mu_{g} \mid \pi^{*}\right)$. The result of the adverse selection spiral is thus either a fixed, equilibrium, point $\pi^{*}$ or an unstable situation where, over time, the premium is constantly being adjusted, up or down. The equilibrium premium, $\pi^{*}$, if it exists and assuming selection is adverse, is such that $\pi^{*}>\pi_{0}$. In practical cases $\pi^{*}$ may be very far from $\pi_{0}=E\left(\mu_{g}\right)$.

A different starting point for the iteration (12) may lead to the same or different equilibrium price, or to non-convergence. This raises issues of convergence and uniqueness.

\section{THE DEMAND FOR INSURANCE}

To assess the likelihood of an adverse selection spiral requires assumptions about the demand for insurance. Theoretical demand curves are often derived from utility functions (Rothschild and Stiglitz, 1976). Individuals are assumed to choose the level of insurance which will maximise their expected utility, taking account of their own wealth, the size of any potential loss, the probability of loss, and premium rates. This approach is more difficult to apply to life insurance and annuity purchases, because:

- life insurance contracts and annuity contracts are not contracts of indemnity,

- as noted previously, the probability of early death is probably correlated with both the level of risk aversion and the wealth of the individual, but this relationship is unknown;

- it is not clear that individuals can assess their own mortality risk very accurately, or evaluate the expected value of the payoff for any long term risk,

- the traditional approach to utility theory assumes that $\$ 1$ before the loss has the same utility as $\$ 1$ after the loss. In the case of life insurance, it is doubtful whether $\$ 1$ in your pocket before death has the same utility as $\$ 1$ in your 
bank account after your death. Theoretically it might be possible to adjust for the utility of a bequest, but in practice it may be difficult to quantify this.

- the demand for life insurance and annuities is complicated by the existence of social insurance schemes. For example, in many developed countries the government provides financial support for the elderly who outlive their savings; the social security system also provides some financial support for widows and orphans. The rules of these social security schemes are often rather complex.

Even if the demand for any individual could be determined, it would still be necessary to determine the theoretical aggregate demand for people in each risk group, making assumptions about the distribution of factors which affect demand for insurance (wealth, number of dependents, risk aversion, and so on); and allowing for the links between each of these factors and mortality risk.

To circumvent these difficulties, suppose the following simple assumptions about the demand for insurance:

- when the premium rate increases, demand will fall

- on average, people with a higher risk level will buy more insurance than people with a lower risk, at a given premium rate (subject to a maximum sum insured determined by the insurer, and a minimum of 0 )

- the demand is a function of the premium loading, defined as the ratio of the premium rate to the actuarially fair value of the insurance i.e. $\pi / \mu_{g}$.

\subsection{A functional form for demand}

The following demand curve is flexible yet practical:

$$
r_{g}(\pi) \equiv E(r \mid g, \pi)=d_{g} e^{1-\left(\pi / \mu_{g}\right)^{\gamma}}, \quad \gamma, \pi>0 .
$$

This demand curve imposes an upper limit on the amount of insurance purchased. This is consistent with the fact that in practice, insurers will not allow customers to buy unlimited amounts of insurance. As the premium loading increases demand falls off to zero.

When the premium rate is set equal to the expected claims cost, $\pi=\mu_{g}$, then the demand is $d_{g}$, and we will call this the "fair premium demand." The elasticity of demand is

$$
\left|\frac{\partial \ln \left\{r_{g}(\pi)\right\}}{\partial \ln (\pi)}\right|=\frac{\gamma}{\mu_{g}}\left(\frac{\pi}{\mu_{g}}\right)^{\gamma} .
$$

The elasticity at $\pi=\mu_{g}$ is $\gamma / \mu_{g}$. The parameter $\gamma$ controls the responsiveness of demand to changes in premium. If $\gamma>\mu_{g}$ the total premium $\pi r_{g}(\pi)$ collected 
from group $g$ at $\pi=\mu_{g}$ decreases if the premium $\pi$ is marginally increased beyond $\mu_{g}$. In the above it is assumed $\gamma$ is constant across the whole population although the example in section 12 allows for variation in $\gamma$ across groups.

The relative rate of desertion of riskiness $g$ compared to riskiness $g^{\prime}$ is $\left(\mu_{g^{\prime}}\right)$ $\left.\mu_{g}\right)^{\gamma}$, and indicates the number $g$ dollars deserting the market for every deserting $g^{\prime}$ dollar as $\pi$ increases. Relative rates of desertion determine the equilibrium premium.

\subsection{Example with two risk groups}

Consider the two-group situation with a low risk group $g=0$ and a high risk group $g=1$. Assume proportion $p=0.05$ of the population is in the high risk category and $\mu_{1}=4 \mu_{0}$ with $\mu_{0}=0.1$ implying $\mu_{1}=0.4$. We also assume that the fair-premium demand is the same for both groups: $d_{0}=d_{1}=1$. If everyone takes out the same amount of insurance, the population average claims cost is 0.115 per unit sum insured. But what happens if the demand for insurance is a function of the risk $g$ and the premium rate $\pi$, as specified by demand curve (13)?

The panels in Figure 2 illustrates some of the possible outcomes. The 45 degree line represents the premium rate and hence revenue per unit sum insured.
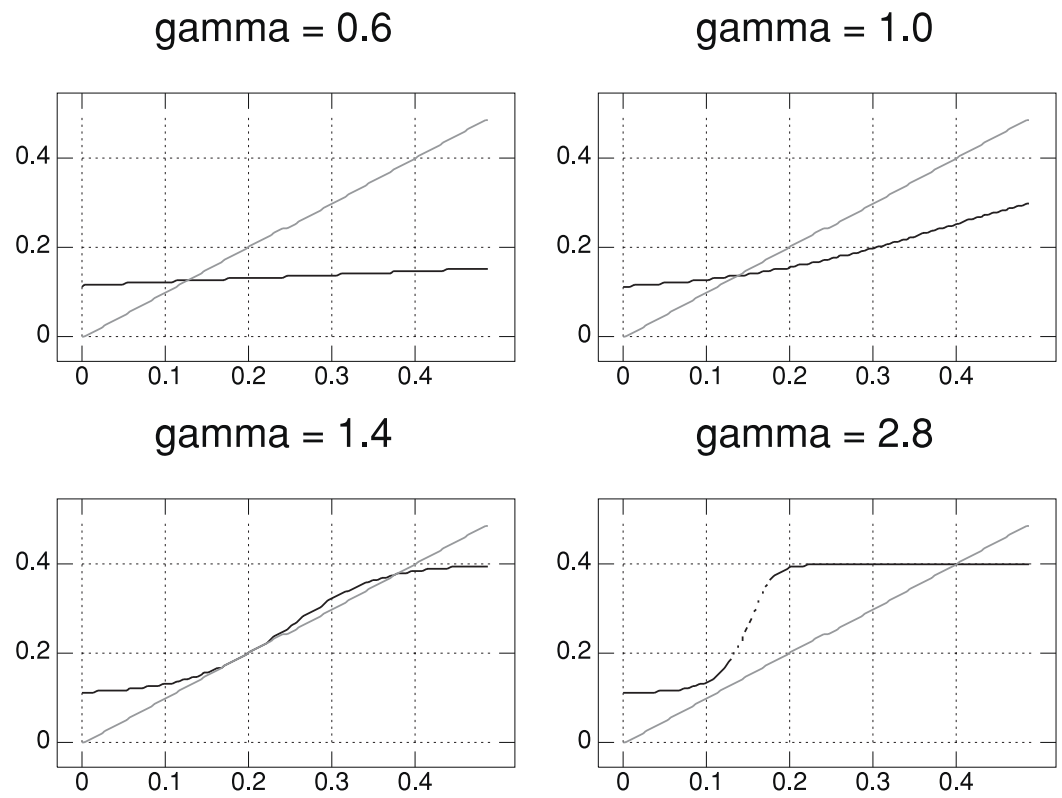

FIGURE 2. Revenue $\pi$ (45 degree line) and expected cost per contract $\varepsilon\left(\mu_{g} \mid \pi\right)$ as functions of $\pi$ for different $\gamma$. Note that $E\left(\mu_{g}\right)=0.115$. The equilibrium premium $\pi^{*}=\varepsilon\left(\mu_{g} \mid \pi^{*}\right)$ in each panel occurs where $\pi$ is such that the two lines intersect. 


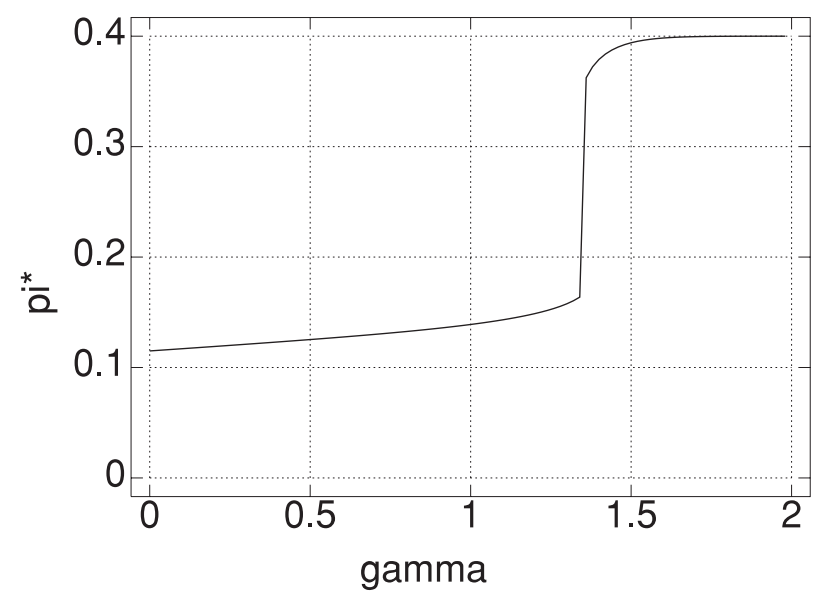

FIGURE 3. Equilibrium premium $\pi^{*}$ as a function of $\gamma$.

The other line represents the average claims cost per unit sum insured. Where these lines intersect, the profits are zero and the system is in equilibrium.

Panel 1 of Figure 2 illustrates the inelastic demand case, where $\gamma=0.6$. The equilibrium price $\pi^{*}=\varepsilon\left(\mu_{g} \mid \pi^{*}\right)$ occurs at $\pi=0.128$, about $11 \%$ above the population mean.

In panel 2, where $\gamma=1.0$, demand is more elastic. As the premium $\pi$ increases the demand from the low risk group falls off quite rapidly, compared to demand from the high risk group, implying significantly higher average cost per contract $\varepsilon\left(\mu_{g} \mid \pi\right)$. The equilibrium price is accordingly significantly higher, at around $\pi=0.139$, or $21 \%$ above the population mean.

The third panel, corresponding to $\gamma=1.4$ displays a moderately elastic case leading to multiple equilibria and an unstable situation over a whole range of premiums. An equilibrium occurs around $\pi=0.166$, but profits will also be zero when the premium rate is about $\pi=0.261$. At $\pi=0.3$ the insurance company is running a loss which can be resolved by pushing premiums higher only to find that losses increase. Finally an equilibrium is again achieved at about $\pi=0.356$ when virtually all the "good" risks have deserted the market. This is the archetypal adverse selection spiral.

The fourth panel of Figure 2 displays a very elastic demand situation $\gamma=2.8$. Even at low premiums $\pi$ the market is dominated by "bad" risks and no equilibrium is attained anywhere near the "good" risk rate of $\mu_{0}=0.1$. Continual upward pressure on the premium leads to progressively bigger losses. Again the market ultimately settles at, effectively, the higher cost rate premium $\pi=0.4$ at which stage nearly all "good" risks are out of the market.

Figure 3 displays the behavior of the equilibrium premium as a function of $\gamma$ for the two group situation discussed above. A critical feature is the jump in the equilibrium premium at around $\gamma \approx 1$.40. It is in this region that there are multiple equilibria. 


\section{AdVERSE SELECTION IN THE ANNUITY MARKET}

The demand model can be used to estimate the impact of changes in the risk classification system. This section considers an example from the annuities market. Historically, in many countries, annuities have been sold using genderbased classification, i.e. there are separate annuity rates for males and females. However, it is often argued that this is discriminatory and should not be permitted. This is especially likely to be an issue when the annuities are provided by employers via employer-sponsored pension funds. In the USA and Canada, certain annuities must be provided on a unisex basis. In 2003, the European Commission issued a proposal for a council directive implementing the principle of equal treatment between men and women in the access to and supply of goods and services (European Commission, 2004), which may lead to the introduction of unisex rating.

Opponents of unisex pricing argue that unisex pricing might lead to an adverse selection spiral. However, without a model for the annuities market, it is difficult to predict the extent of market disruption which would arise. Curry and O'Connell (2004) contains a discussion of the potential impact of unisex rating on the UK annuities market.

To estimate the effect of unisex pricing this section proposes the following steps:

- Demand responsiveness is estimated from differences between population mortality rates and annuitants' mortality rates. Demand responsiveness is determined by fitting the demand function (13) by determining $\gamma$. Thus is done for both females and males.

- Given $\gamma$ we find the equilibrium premium $\pi^{*}$ for both males and females separately. This gives the gender based premium rates.

- We then find the equilibrium premium when the two markets are merged. This new equilibrium unisex premium will lie between the male and female equilibrium premiums, depending on the demand responsiveness of the two groups and the relative propensity for insurance for the two groups.

\subsection{Estimating demand responsiveness}

Consider a population of about-to-retire males, all aged 65 . The men must decide whether or not to purchase an annuity. Assume the only product available is an indexed annuity payable in advance until age 100 , and the real rate of return is $3 \%$ p.a.

Suppose members of the population have different mortality risk. Let $g$ denote the frailty of a randomly selected individual, so that the probability that a person alive at time $t$ will die in the following year is $g q(t)$, where $q(t)$ is a standard rate of mortality applicable to males. The probability that a randomly chosen male will have frailty $g$ is given by $p(g)$. Assume $\ln (g)$ is distributed normally with mean $\mu$ and variance $\sigma^{2}$. As $\sigma^{2}$ approaches 0 , the elasticity parameter 
$\gamma$ will have to be very large to amplify the small variations in male mortality in the population into the substantial differences between annuitant and population mortality. When $\sigma^{2}$ is large, even small demand responsiveness might lead to a large adverse selection effect on mortality experience.

In practice, $p(g)$ can be estimated by considering the market for enhanced and impaired life annuities (Ainslie, 2000) or may be deduced from studies of factors affecting retirement mortality (Brown and McDaid, 2003).

Each frailty $g$ implies a survival function $s_{g}(t)$, showing the probability of survival for another $t$ years. The fair value cost of providing a pension of $\$ 1$ pa. payable in advance until death, denoted $\mu_{g}$ can be worked out for each $g$ from $s_{g}(t)$ at any given interest rate. The expected person remaining lifetime probabilities are

$$
E\left\{s_{g}(t) g q(t)\right\}=q(t) E\left\{g s_{g}(t)\right\}, t=0,1, \ldots,
$$

where the expectation is with respect to $p(g)$.

The mortality rates for the overall population are available. Denote the population remaining lifetime probabilities by $f_{p}(t), t=0,1, \ldots$. Then equating the observed and expected remaining lifetime probabilities permits $q(t)$ to be determined. The recursive equations are

$$
q(t)=\frac{f_{p}(t)}{E\left\{g s_{g}(t)\right\}}, s_{g}(t+1)=s_{g}(t)\{1-g q(t)\}, t=0,1, \ldots,
$$

where $s_{g}(0)=1$. The remaining lifetime probabilites for frailty group $g$ are then $f_{g}(t)=g q(t) s_{g}(t)$.

Now suppose the expected amount of annuity purchased by a person with frailty $g$ at given market premium $\pi$ is $r_{g}(\pi)$. Then the amounts-weighted deferred death probabilities for the annuitants are

$$
\varepsilon\left\{f_{g}(t) \mid \pi\right\} \equiv \frac{E\left\{r_{g}(\pi) f_{g}(t)\right\}}{E\left\{r_{g}(\pi)\right\}}, t=0,1, \ldots .
$$

We can observe the amounts-weighted mortality for a group of annuitants: for example the Institute and Faculty of Actuaries produce amounts-weighted mortality rates for UK annuitants, and historical data on market annuity rates are also available. Assuming all risk groups have the same fair-premium demand, permits the estimation of the elasticity parameter $\gamma$. This may be done by equating the observed and expected annuitant mortality rates, and then choosing $\gamma$ so as to minimize the Kolmogorov-Smirnov statistic:

$$
\hat{\gamma}=\operatorname{argmax}_{\gamma}\left\{\max _{t}\left|s_{a}(t)-s_{\gamma}(t)\right|\right\}
$$

where $s_{a}(t)$ is the survival function of the annuitants and $s_{\gamma}(t)$ is the survival function based on $\varepsilon\left\{f_{g}(t) \mid \pi\right\}$ evaluated at $\gamma$. 


\subsection{Finding the equilibrium premium}

The equilibrium can be determined given $\hat{\gamma}$. Allowing for the insurer's proportional loading $\kappa$ for expenses, profits and risk transfer, the equilibrium premium is determined by solving, for $\pi^{*}$, the equation

$$
\pi^{*}=(1+\kappa) \varepsilon\left(\mu_{g} \mid \pi^{*}, h\right),
$$

where $h=0$ for males and $h=1$ for females. In practice, money's worth calculations, such as those given in Murthi et al. (1999) can be used to estimate the appropriate loading factor $\kappa$. In the application below, it is assumed $\kappa=0.10$.

If the market allows gender-based rating, then separate analyses can be carried out for males and females. If there are gender differences in price sensitivity (e.g. because of differences in risk aversion), then $\gamma$ for females may be different to the male $\gamma$.

\subsection{Determining the impact of unisex annuity pricing}

Suppose that the market is in equilibrium under a gender-based pricing system, with separate annuity rates for males and females. Then unisex pricing is introduced.

Under unisex rating the equilibrium price is $\pi^{\dagger}$ is such that

$$
\pi^{\dagger}=(1+\kappa) \varepsilon\left\{\varepsilon\left(\mu_{g} \mid \pi^{\dagger}, h\right)\right.
$$

where the outer expectation averages over $h$ using relative money-weighted demand originating from the female and male groups. The application below considers two different scenarios.

\subsection{Application to UK data}

This section applies the methodology to the UK annuities market. In particular

- Population mortality is taken from UK Government Actuary's Interim Tables for 1990-1992 (Government Actuary's Department, 2005);

- Annuitant mortality is based on the amounts-weighted annuitant rates given in (Wilkie et al., 1999, Tables A6 and A7);

- Annuity values were calculated as immediate lifetime annuities payable in advance from age 65 to age 100 . The valuation rate was 3\% p.a., representing a real rate of return for an indexed pension. This assumes that all annuitants are buying indexed annuities with no guarantee period and no reversionary benefits.

- The distribution of frailty was assumed to follow a lognormal distribution with $\mu=0.25$ and $\sigma^{2}=0.20$. This ensures that roughly two thirds of 
females

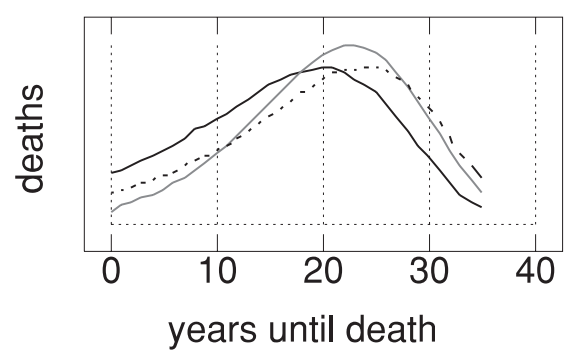

males

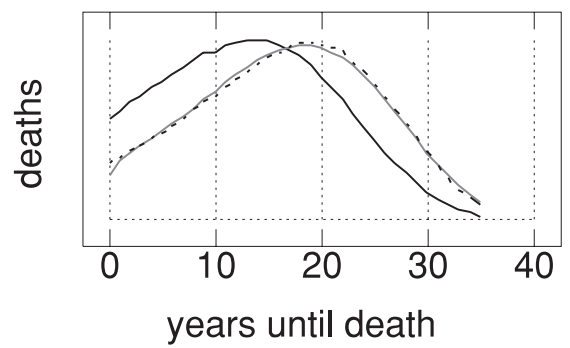

FIgURE 4. Actual and fitted mortality probabilities. The dotted lines are the fitted probabilities.

the population would be classified with mortality rates up to $150 \%$ of the standard

- The insurer's loading $\kappa$ is set at $10 \%$. This is the loading assumed to apply to both the past data and the future.

- Within each gender group, fair premium demands $d_{g}$ are assumed independent of $\mu_{g}$. Thus in the calculation of $\varepsilon\left(\mu_{g} \mid \pi\right)$ for each gender, we cancel out $E\left(d_{g}\right)$ in both the numerator and denominator. Hence $d_{g}$ can be ignored when determining gender specific equilibrium premiums.

Figure 4 displays the probabilities of death at age $65+t$ for someone who is now aged 65 , based on (i) the population mortality rates (ii) the annuitant mortality rates, and (iii) the rates arising from our fitted model. The male mortality shows a better fit than the female mortality. The fitted values of $\gamma$ are displayed in Table 3.

Using the annuitant mortality tables and an interest rate of 3\% p.a., the fair value of an annuity due, $\ddot{a}_{65: \overline{36} \mid}$ was calculated for each of 100,000 simulated frailties for both males and females. Using the estimated gender specific values of $\gamma$, equilibrium premium rates $\pi^{*}$ were calculated for a market which allows gender-based rating. These results are displayed in Table 3. As expected, the male equilibrium premium produced an expected model claims cost of 13.53 which is close to the Wilkie et al. (1999) annuitant rate of 13.55. This reflects the fact that the model is a good fit for the male data. However there is some discrepancy for the females: the assumed market premium implies a model claims rate of 15.43 compared to the Wilkie et al. (1999) rate of 15.67.

The equilibrium premium rate under unisex pricing depends on the further assumption about the relative money weighted proportions of female and male annuitants. Assuming that they are equal, we can predict the total demand for annuities for both males and females at each premium. As shown in the Table 3 , the ratio of female to male demand would be approximately 30:25. 
TABLE 3

GENDER BASED AND UNISEX ANNUITY RESULTS*

\begin{tabular}{|c|c|c|c|}
\hline Basis & Quantity & $\begin{array}{c}\text { females } \\
h=1\end{array}$ & $\begin{array}{c}\text { males } \\
h=0\end{array}$ \\
\hline Government Actuary's Department (2005) & $\ddot{a}_{65: \overline{36} \mid}=E\left(\mu_{g} \mid h\right)$ & 13.75 & 11.47 \\
\hline Wilkie et al. (1999) & $\ddot{a}_{65: \overline{36} \mid} \approx \varepsilon\left(\mu_{g} \mid \pi^{*}, h\right)$ & \multirow{2}{*}{$\begin{array}{r}15.67 \\
4.59\end{array}$} & 13.55 \\
\hline & $\hat{\gamma}$ & & 4.29 \\
\hline gender & $\pi^{*}=(1+\kappa) \varepsilon\left(\mu_{g} \mid \pi^{*}, h\right)$ & 16.98 & 14.88 \\
\hline \multirow[t]{2}{*}{ based } & $E\left\{r_{g}\left(\pi^{*}\right) \mid h\right\}$ & \multirow{2}{*}{$\begin{array}{r}0.30 \\
15.43\end{array}$} & 0.25 \\
\hline & $\varepsilon\left(\mu_{g} \mid \pi^{*}, h\right)$ & & 13.53 \\
\hline \multirow[t]{5}{*}{ unisex } & $\varepsilon(h)$ & \multicolumn{2}{|c|}{0.5} \\
\hline & $\pi^{\dagger}=(1+\kappa) \varepsilon\left(\mu_{g} \mid \pi^{\dagger}\right)$ & \multicolumn{2}{|c|}{16.54} \\
\hline & $E\left\{r_{g}\left(\pi^{\dagger}\right) \mid h\right\}$ & 0.36 & 0.10 \\
\hline & $\varepsilon\left(\mu_{g} \mid \pi^{\dagger}, h\right)$ & 15.33 & 14.04 \\
\hline & $\%$ change in demand & 22 & -59 \\
\hline \multirow[t]{5}{*}{ unisex } & $\varepsilon(h)$ & & \\
\hline & $\pi^{\dagger}=(1+\kappa) \varepsilon\left(\mu_{g} \mid \pi^{\dagger}\right)$ & \multicolumn{2}{|c|}{16.67} \\
\hline & $E\left\{r_{g}\left(\pi^{\dagger}\right) \mid h\right\}$ & 0.34 & 0.10 \\
\hline & $\varepsilon\left(\mu_{g} \mid \pi^{\dagger}, h\right)$ & 15.36 & 14.08 \\
\hline & $\%$ change in demand & 15 & -62 \\
\hline
\end{tabular}

* Based on $\kappa=0.10$.

However, the male and female population is observed and the total amount of annuities purchased by males and females can be observed. For example, in Wilkie et al. (1999, Table 2.1), showing data for UK immediate annuitants in the period 1991-1994, females purchased annuities of £13.1 million p.a. compared to male annuities of $£ 8.6$ million p.a. This data suggests that the fair premium demand from females is higher than the fair premium demand from males, in the voluntary annuity market. Hence we might adjust the fair premium demands $d_{g}$ to reflect this difference. In the following example, we consider two alternatives: (i) money weighted demand for females equals that of males, and (ii) money weighted demand for females is 1.5 times that for males. These two scenarios are indicated in the two unisex panels.

Using the above two scenarios, the fitted model can be used to project the effect of any changes to the rating structure, e.g. to determine whether an adverse selection spiral would be likely to arise. For example, suppose that the government introduces legislation which requires unisex pricing for annuities, and the initial premium rate is set to be the average of the male and female annuitant premium rates. How would the demand change? Would the system stabilise or spiral out of control? 
If unisex rating was introduced, and if there was no change in demand as a result of the change in the pricing structure, then the expected claims rate would be a weighted average of the male and female premium rates with weights given by the proportions of money weighted demand. However, our model allows for the fact that unisex pricing will lead to a change in demand. Females will buy more, and males will buy less. There is an adverse selection spiral of sorts in that the premium moves towards that of the higher cost female group. As a result, the equilibrium premium will be higher. The results of this unisex analysis are shown in Table 3.

Using equal money weighted demand of female and male annuitants, the equilibrium premium is 16.54 . Thus for females, the premium rate falls slightly, from 16.98 to 16.54 , i.e. a $3 \%$ reduction. As a result, the level of female demand increases by $22 \%$, from 0.30 to 0.36 . At these lower premium rates, some of the women who are in poorer health will now find it advantageous to buy an annuity, and hence the average value of benefits will fall slightly, from 15.43 to 15.33.

For the males, the switch to unisex rating creates an increase in premium from 14.88 to 16.54 ; a $59 \%$ reduction in demand from 0.25 to 0.10 ; and an increase in the average benefit value from 13.53 to 14.04 as more of the unhealthy males decide against purchasing annuities at such a high premium rate.

In this case the adverse selection effect, arising from the changes in demand, leads to a premium rate which is roughly $6 \%$ higher than expected simply from averaging the gender based premium rates: 16.97 instead of 16.02 . Hence the model predicts that the unisex market will stabilise at a rate which is only slightly below the rate for females. Although female demand will rise, the overall demand will fall as males desert the market.

Unisex rating will create a cross subsidy from males to females. The average cost of females benefits (including insurer's expense and profit loading) is $1.1 \times 15.33=16.86$, whereas they will pay only 16.54 in premiums. The average cost of males benefits (including insurer's expense and profit loading) is 15.44, whereas they will pay 16.54 in premiums. Thus while premiums move only marginally, the significant cost to society appears to be in the drastic reduction in male demand.

If there is a prior money-weighted probability of females taking up annuities, using a ratio $3: 2$, then the equilibrium premium is slightly higher at 16.67 , and this flows through again to changes in demand and average benefit levels as shown in the final rows of Table 3.

\section{CONCLUSION}

Risk classification is controversial: although insurers may wish to charge premiums which vary according to the level of risk, public policy pressures may require some cross subsidies between risk groups. This creates the risk of adverse selection. In our paper, we have shown how adverse selection costs can be quantified; we have discussed various methods for managing and controlling 
the costs of adverse selection; and we have assessed the benefits of applying proxy rating factors. Essentially, the management of adverse selection requires an understanding of the relationship between insurance risk and the demand for insurance: a relationship which may well be more complex than suggested by some of the economic models which have traditionally been used for analysis of this problem.

When legislators impose restrictions on rating factors, this can create instability in the market, potentially increasing costs and reducing the availability of insurance. In order to assess the costs and benefits of any such legislative proposals, we need a model which allows the demand for insurance to vary with the premium rate and the risk. The demand model and methodology proposed in this paper provides a useful framework for gaining detailed insights into the equilibrium behavior of insurance markets, taking account of the distribution of risks, the premium sensitivity of demand, and the rating structure.

\section{REFERENCES}

AinsLie, R. (2000) Annuity and insurance products for impaired lives. Presentation to the Staple Inn Actuarial Society.

American Academy of Actuaries Committee on Risk Classification (1980) Risk classification. Statement of Principles.

Armstrong, K., Weber, B., FitzGerald, J., Hershey, G., Pauly, M., Lemaire, J., SubramaNIAN, K, and Asch, D. (2003) Life insurance and breast cancer risk assessment: Adverse selection, genetic testing decisions, and discrimination. American Journal of Medical Genetics 120A(3), 359-64.

Australian Bureau of Statistics (2001) Deaths. Catalogue number 3302.0.

Babbage, C. (1826) A Comparative View of the Various Institutions for the Assurance of Lives. New York: AM Kelley. Reprinted in 1967.

Banks, G., Owen, H., and Kearney, B. (1997) Private health insurance. Industry Commission Inquiry 57, Australian Government Publishing Service, Canberra.

Barn, G., Berry, P., Brien, A., Bui, H., Burgess, F., Chan, P., Clarke, S., Hui, C., Knight, R., Longden, D., Mak, A., Service, D., Turner, S., and Whittaker, G. (2004) Report on the Lump Sum Experience Investigation 1998-1999. Institute of Actuaries of Australia Life Risk Insurance Committee.

Bowers, N., Gerber, H., Hickman, J., Jones, D., and Nesbitt, C. (1986) Actuarial Mathematics. Itasca, Illinois: Society of Actuaries.

BRown, R.L. and MCDAID, J. (2003) Factors affecting retirement mortality. North American Actuarial Journal 7(2), 24-43.

BüHlmann, H. (1970) Mathematical methods in risk theory. Berlin: Springer-Verlag.

Chuffart, A. (1995) Genetic underwriting. Paper presented to the Actuarial Life Convention, Glasgow, December 1995.

Curry, C. and O'Connell, A. (2004) An analysis of unisex annuity rates. Working Paper Series Report 16, Equal Opportunity Commission.

De RaVIn, J. and Rump, D. (1996) The right to underwrite. The Institute of Actuaries of Australia Quarterly Journal (September).

DiCKSON, P. (1960) Sun Insurance Office Ltd, 1710-1960: the history of two and a half centuries of British insurance. Oxford: Oxford University Press.

Doeer, T.S. (1984) Sex-based actuarial assumptions, Title VII, and the Equal Pay Act: employee benefit planning following Manhart and Norris. Rutgers Law Review 36(4), 839-860.

Doyle, S., Mitchell, O., and Piggott, J. (2002) Annuity values in defined contribution retirement systems: Australia and Singapore compared. Research Discussion Papers 2-02, University of New South Wales Centre for Pensions and Superannuation Research. 
EUROPEAN COMMISSION (2004) Implementing the principle of equal treatment between women and men in the access to and supply of goods and services. Council Directive 2004113EC, European Commission.

Finkelstein, A. and Poterba, J. (2002) Selection effects in the United Kingdom individual annuities market. The Economic Journal 112, 28-50.

Gerber, H. (1990) Life Insurance Mathematics. Berlin: Springer-Verlag.

Government Actuary's Department (2005) UK Government Actuary: Interim Tables for 19901992.

HALL, C. (1991) Insurance firms retain bias over HIV tests, according to AIDS working party report. The Independent. March 6, 1991.

HaLl, M. (1999) Restricting insurers use of genetic information: A guide to public policy. North American Actuarial Journal 3(1).

Harper, P. (1992) Huntington disease and the abuse of genetics. American Journal of Human Genetics 50, 460-464.

HARRIS, P. (1994) New AIDS question for UK life insurance. Reuters News. 26 July 1994.

Hellman, D. (1997) Is actuarially fair insurance pricing actually fair?: A case study in insuring battered women. Harvard Civil Rights - Civil Liberties Law Review 32, 355.

Hoem, J. (1969) Markov chain models in life insurance. Blatter der Deutschen Gessellschaft fur Versicherungsmathematik 9(2), 91-107.

HoEm, J. (1988) The versatility of the Markov chain as a tool in the mathematics of life insurance. Transactions of the 23rd International Congress of Actuaries R, 171-202.

Hoffman, F. (1900) History of the Prudential Insurance Company of America (Industrial Insurance) 1875-1900. Newark New Jersey: Prudential Press.

Hopegood, J. (1990) Department of health survey to examine AIDS test fears. Money Marketing. 20 December 1990.

Hurd, M. and MCGARrY, K. (2002). The predictive value of subjective probabilities of survival. Economic Journal 112, 966-985.

JONES, J. (1991) Insurance companies' life cover questions stop thousands having AIDS test. The Independent. 25 July 1991.

Knox, D. and Tombin, A. (1997) An analysis of pensioner mortality by pre-retirement income. Centre for Actuarial Studies Research Paper Series 44, University of Melbourne.

Lapham, E., Chahira, K. and Weiss, J. (1996) Genetic discrimination: Perspective of consumers. Science 274(5287), 621-625.

LE GRYs, D. (1998) Life underwriting and reassurance. In D. Renn (Ed.), Life, Death, and Money: Actuaries and the creation of financial security, Chapter 9, pp. 165-177. Blackwell Publishers.

LeIGH, T. (1990) Underwriting - a dying art? Journal of the Institute of Actuaries 117, 443-532.

LeIGH, T. (1996) The freedom to underwrite. Presentation to the Staple Inn Actuarial Society.

MacDonald, A. (2000) Human genetics and insurance issues. In I. Torrance (Ed.), Bio-ethics for the new millenium. St Andrew Press.

MacDOnALD, A.S. (1997) How will improved forecasts of individual lifetimes affect underwriting? British Actuarial Journal 3(15), 1009-1025.

MacDOnAld, A.S. (1999) Modeling the impact of genetics on insurance. North American Actuarial Journal 3(1), 83-101.

McGarry, K. and Finkelstein, A. (2003) Private information and its effect on long term equilibrium: New evidence from long term care insurance. Working Paper Series 9957, National Bureau for Economic Research.

Meikle, J. (1886) On the official publications of the mortality of assured lives. Transactions of the Actuarial Society of Edinburgh I.

Mitchell, O. and McCARTHY, D. (2001) Estimating international adverse selection in annuities. Working Paper Series 12, Pension Research Council.

Murthi, M., Orszag, J., and Orszag, P. (1999) The value for money of annuities in the UK: Theory, experience and policy. Birbeck Working Papers in Economics and Finance 19/99, University of London.

NicolL, J. (1904) Life assurance without medical examination. Transactions of the Faculty of Actuaries II, 57-89.

NoRBERG, R. (1995) Differential equations for moments of present values in life insurance. Insurance: Mathematics \& Economics 17, 171-180. 
Nova Scotia Insurance Review Board (2004) A study into the use of gender as a rating factor in automobile insurance in Nova Scotia. Report to the governor in council.

PAPWORTH, J. (1991) Insurance industry acts to ease worries over HIV tests. The Guardian. 6 April 1991.

Pauly, M.V., Withers, K.H., Subramanian, V.K., Lemaire, J., Hershey, J.C., Armstrong, K., and Asch, D.A. (2003) Price elasticity of demand for term life insurance and adverse selection. Working Paper W9925, National Bureau for Economic Research.

PhiliPSON and CAWLEy (1996) An empirical examination of information barriers to trade in insurance. Working Paper 5669, National Bureau for Economic Research.

Promislow, S. (1987) Measurement of equity. Transactions of Society of Actuaries 39, 215-256.

RothschiLD, M. and STiglitz, J. (1976) Equilibrium in competitive insurance markets: The economics of markets with imperfect information. Quarterly Journal of Economics 90, 629-649.

Rothschild, M. and STiglitz, J. (1997) Competition and insurance twenty years later. The Geneva Papers on Risk and Insurance Theory 22, 73-79.

Skipper, H. and Black, K. (2000) Life and Health Insurance (13 ed.). Prentice Hall.

Society of Actuaries Individual Life Experience Committee (2004) Mortality under standard individually underwritten life insurance between 1995 and 2000 policy anniversaries. Mortality experience studies.

SPENS, W. (1854) On the inadequacy of existing data for determining the rate of mortality among select lives. The Assurance Journal IV, 1-9.

Stenhouse, G. (1886) The mortality of assured lives viewed in relation to the sums at risk. Transactions of the Actuarial Society of Edinburgh II.

Subramanian, K.J. and Lemaire, A.S. (1999) Estimating adverse selection costs from genetic testing for breast and ovarian cancer: The case of life insurance. Journal of Risk and Insurance 66(4), 531-50.

Subramanian, K., Lemaire, J., Hershey, J., Pauly, M., Armstrong, K., and Asch, D. (1999) Estimating adverse selection costs from genetic testing for breats and ovarian cancer: The case of life insurance. Journal of Risk and Insurance 66, 531-550.

Sullivan, M. (1991) AIDS issues polarises the insurance industry, pressure groups, and the government. Post Magazine. 31 October 1991.

Thomas, R. (2001) Genetics and insurance. Response to the Human Genetics Commission Public Consultation.

Wilkie, A., McCutcheon, J., Forfar, D. and Leandro, P. (1999) Standard tables of mortality based on the 1991-94 experience. Continuous Mortality Investigation Report 17, Institute of Actuaries and Faculty of Actuaries Continuous Mortality Investigation Bureau.

WORSFOLD, D. (1991) Viscount Falkland attacks insurance industry lifestyle questions. Post Magazine. 14 February 1991.

Wright, W., Bakel, L., Monaghan, J., Szczepanski, C., Taylor, R., Wickman, A., Woods, P., DiETER, G. and VASS, G. (2002) The use of credit history for personal lines of insurance: report to the national association of insurance commisioners. Report to the NAIC, American Academy of Actuaries Risk Classification Subcommittee.

\section{PIET DE Jong}

Department of Actuarial Studies,

Macquarie University,

NSW 2109, Australia.

Email: piet.dejong@mq.edu.au 